\title{
Statistical Analysis for Study of the Effect of Dark Clothing Color of Female Pedestrians on the Severity of Accident Using Machine Learning Methods
}

\author{
Seyed Mohsen Hosseinian (D), ${ }^{1}$ Vahid Najafi Moghaddam Gilani ${ }^{(D)},{ }^{1}$ Babak Mirbaha $\left(\mathbb{D},{ }^{2}\right.$ \\ and Ali Abdi Kordani ${ }^{2}$ \\ ${ }^{1}$ School of Civil Engineering, Iran University of Science and Technology (IUST), Tehran, Iran \\ ${ }^{2}$ School of Civil Engineering, Imam Khomeini International University (IKIU), Qazvin, Iran \\ Correspondence should be addressed to Seyed Mohsen Hosseinian; sm_hoseinian@civileng.iust.ac.ir
}

Received 3 March 2021; Revised 20 March 2021; Accepted 24 March 2021; Published 14 April 2021

Academic Editor: Noorbakhsh Amiri Golilarz

Copyright (c) 2021 Seyed Mohsen Hosseinian et al. This is an open access article distributed under the Creative Commons Attribution License, which permits unrestricted use, distribution, and reproduction in any medium, provided the original work is properly cited.

\begin{abstract}
The color and brightness of pedestrian clothing are among the factors that could increase the severity of their accidents due to the lack of visibility, especially at night. Today, as most Iranian females tend to wear hijab or dark clothing, the necessity of investigating female pedestrian accidents influenced by clothing color is important. Many studies have been performed to analyze the severity of pedestrian accidents, but a study has not yet been conducted to determine the effect of the dark clothing color of female pedestrians on the severity of accidents. Therefore, in this study, 12 independent variables affecting the severity of female pedestrian accidents such as clothing color, age, accident time, day, weather condition, education, pedestrian action, crossing facilities, crossing permit, job, road classification, and fault status were studied. Frequency analysis, Friedman test (FT), and Factor Analysis (FA) methods, as well as modeling methods of Multiple Logistic Regression (MLR) and Artificial Neural Networks (ANNs) using Multilayer Perceptron (MLP) and Radius Basis Function (RBF), were used. Results indicated that clothing color had a significant influence on pedestrian accidents, and chador and dark clothing color increased the probability of accidents, especially at night. The MLP model had a better prediction percentage than the rest, the prediction accuracy of which was $94.6 \%$. Finally, safety solutions were presented according to the results to reduce pedestrian accidents and increase road safety.
\end{abstract}

\section{Introduction}

Walking is one of the forms of transportation that can connect a private environment with the community in the absence of other means of transportation [1]. Each person is a pedestrian during a day at different times depending on his/her activity, mode selection, or travel plan. So it is important to consider pedestrian safety along with other road users [2,3]. Traffic management is an important issue in developed countries, and the government should invest substantially in this case for an effective transportation network $[4,5]$. If no measure is taken to reduce accidents and increase road safety, the rate of accidents and casualties will always increase and result in the loss of financial and human resources [6-7].

Thousands of people are disabled or injured with longlasting effects annually, which imposes considerable expenses on families and societies. Road Traffic Accidents (RTAs) today represent the eighth leading cause of death globally. Deaths from RTAs have increased to 1.35 million a year and caused up to 50 million injuries in 2016. In Iran, the reported number of road traffic deaths was 15,932 in 2016. Also, the estimated traffic fatality rate per 100,000 population was 20.5 [8]. So, deaths caused by Road Traffic Injuries (RTIs) should be of particular concern in Iran [9]. According to police data, the number of fatal pedestrian 
accidents in Tehran from March 2017 to March 2018 was 8,582 and from March 2018 to March 2019 was 9,217. A comparison of pedestrian accidents in 2018 with 2017 shows an accident rate growth of $7.7 \%$ [10].

Pedestrians are the most vulnerable users of the highway transportation system. Various factors contribute to traffic accidents. These causes could be analyzed and useful measurements should be taken in order to reduce accidents [11-13]. Therefore, recognition of pedestrian behavior is useful in controlling and managing the transportation network [14].

In Iran, as females are required by law to wear hijabs, such as chador or other Islamic clothing, and because of their tendency to wear chador and dark clothing, a study is needed to examine the impact of their clothing on the severity of pedestrian accidents. Therefore, in this study, the effect of the dark clothing color of female pedestrians on the rate of accidents was investigated, and some strategies were presented to improve their safety.

Many studies indicated the importance of clothing color in the safety and severity of pedestrian accidents. A study was conducted by Turner et al. [15] to specify the most visible color of safety clothing in daylight for protecting the personnel in the construction of a highway. Eleven different colors were examined, including one semifluorescent color (yellow), two nonfluorescent colors (orange and yellow), and eight fluorescent colors (yellow, green, yellow-green, redorange, yellow-orange, red mesh over white background, a combination of yellow-green with red-orange, and pink). They found the highest mean detection distance by the fluorescent red-orange colored vests. Clifton et al. [16] examined the effect of environmental and personal features on the severity of injuries in vehicle-pedestrian accidents. They found that pedestrians with dark clothing color had a lower rate of accidents compared to those wearing mixed or light clothing. Moreover, compared to those wearing lighter clothing, pedestrians with dark clothing color were also less likely to be killed or injured. These findings may be because the majority of accidents, almost $70 \%$, happened during the day. Tyrrell et al. [17] examined the effect of extraneous points of light on the capability of 12 older and 12 younger drivers in seeing pedestrians while driving on a closed road at night. Pedestrians had black clothing alone or clothing with retro-reflective markings in 4 various configurations. They found that pedestrian motion and clothing configuration had an effect on the conspicuity.

A high number of pedestrian collisions and fatalities was reported by Zegeer and Bushell [18], occurring at night or under low-lighting circumstances. A study was performed by Wood et al. [19] on quantifying the impacts of driver's age on the conspicuity of the nighttime pedestrian and the capability of drivers in recognizing the pedestrians at night. They found that driver's age and pedestrian's clothing had a considerable effect on the distance at which the drivers initially reacted to the presence of pedestrians. When pedestrians wore a biological motion reflective clothing, they were recognized more often than when they wore a reflective vest. Borzendowski et al. [20] explored the accuracy of drivers' judgment from pedestrian conspicuity in each of the two clothing configurations while facing varying degrees of headlight glare. Their research found that by wearing a retroreflective vest by the pedestrian, the overestimated conspicuity of participants was higher.

A research was performed by Hefny et al. [21] to analyze the severity and consequence of hospitalized trauma of pedestrian patients involved in an accident. They found that pedestrian collisions at low-lightning circumstances or nighttime had the greatest percentage and stated that the use of visibility aids, including the use of light-colored clothing or inexpensive reflective vests over the night, needs to be encouraged via public campaigns. Pour-Rouholamin and Zhou [22] studied the risk factors related to different injury severity levels experienced by pedestrians. The results showed that pedestrians increased the severity of injuries without contrasting and dark clothing. They also found that these pedestrians were more susceptible to severe injuries in comparison with those wearing contrasting clothing.

Fekety et al. [23] assessed the nighttime conspicuity advantages of the addition of electroluminescent (EL) panels in pedestrian clothing containing retro-reflective components. They indicated that the garment, including retroreflective substances and EL, obtained longer response distances compared to the retroreflective-only garment. Besharati and Tavakoli Kashani [24] investigated Iranian crash data provided by Iranian traffic police. They showed that by both pedestrian dark clothing and illumination, the crashes that occurred on an urban highway were 9 times more likely to be fatal. Baireddy et al. [25] assessed the factors affecting pedestrian accidents in Illinois. They found that pedestrians not wearing contrasting clothing were involved in $66.29 \%$ of accidents. In addition, they were less visible and more susceptible to crashes.

Wickramasinghe et al. [26] provided a study to determine the visibility distance from the pedestrian. Detection distances were calculated for 5 pedestrian clothing colors (yellow, red, black, white, and retro-reflective). Based on the results, drivers' detection distance was remarkably influenced by the clothing color of the crossing pedestrian and headlamp light conditions. Retro-reflective color was identified to have the longest detection distance, followed by white color. Also, black color had the lowest detection distance. Abdous and Mahmoudabadi [27] explored the female pedestrian fatalities in Iran in terms of their death location and other parameters such as visibility (clothing color), day time, and age. The findings revealed that the vulnerability of female pedestrians to accidents had no considerable difference in different times of the day; however, wearing dark clothing (often chador as a prevalent robe in Iran) remarkably increased their vulnerability. Moreover, recently, well-established optimization algorithms with flexible exploratory and exploitative tendencies have been applied to various designs and engineering problems [28-45].

Modeling the severity of accidents in terms of their effective parameters makes it possible to predict the occurrence of accidents requiring relief equipment. Various feature selection and learning methods [40-58] can also be applied as a preprocessing step to these prediction cases. In 
addition, using this model, the effect of each factor in intensifying accidents can be investigated. Such recognition will lead to the possibility of formulating traffic safety plans for traffic engineers, and they may also have a better understanding of the factors that have a positive or negative impact on the severity of accidents. Therefore, the aims of this study were as follows:

(1) Investigating the effect of clothing color of female pedestrians on the severity of their accidents

(2) Frequency analysis of variables affecting the accidents of the female pedestrian with dark clothing

(3) Modeling the independent variables affecting the severity of their accidents

(4) Comparison of accident models and analyses with each other and other related studies

\section{Methodology}

2.1. Study Area. This research was performed in the Tehran metropolis, which is the capital of the Tehran province and Iran. Tehran is the most populous metropolis in the country and western Asia, and includes 22 districts spread across 730 square kilometers and is located at $51^{\circ} 17^{\prime}$ to $51^{\circ} 33^{\prime} \mathrm{E}$ and $35^{\circ} 36^{\prime}$ to $35^{\circ} 44^{\prime} \mathrm{N}$ and also is 900 to 1800 meters above sea level. According to the official census in 2016, its population was $8,693,706$, of which $4,369,551$ were female, and the female population density was announced as 5,986 per square [59].

2.2. Data Collection. Information on pedestrian accidents in this study was collected from March 2017 to March 2019 from the Tehran traffic police. Among the recorded variables, female accidents were selected to examine the variables of clothing color, age, accident time, day, weather condition, education, pedestrian action, crossing facilities, crossing permit, job, road classification, and fault status. The total number of pedestrian accidents was 18251, of which 6128 were female pedestrian accidents, among which 3962 were female pedestrian accidents with dark clothing, indicating the high importance of female pedestrians with dark clothing in accidents. Finally, considering the abovementioned variables, the severity of female pedestrian accidents in Tehran was analyzed.

2.3. Description of Variables. In this study, the data of female pedestrian accidents in Tehran from March 2017 to March 2019 were used, which totally included 13 variables in 6128 accidents. The dependent variable in this research was accident severity, which was divided into two types: accidents inflicting injuries and fatal accidents. These variables were coded to begin modeling, as shown in Table 1 .

\subsection{Methods}

2.4.1. Kolmogorov-Simonov (K-S) Test. The $\mathrm{K}-\mathrm{S}$ test is a nonparametric test for data distribution and is generally applied to explore data normality. In the approximate significance test, by comparing the significance level and $\alpha$, one can decide the normality of data distribution. By considering $\alpha=0 / 05$ (in $95 \%$ certainty), if $p$ value $>0 / 05$ can be assumed, data distribution will be normal [60].

2.4.2. Friedman Test (FT). The FT test is an extensively used nonparametric technique to compare the classifiers over multiple datasets. It is commonly applied to analyze different associated samples in various fields. For instance, FT is utilized for comparing the performance consequences of a group of classifiers over multiple datasets that cover benchmark functions, case problems, or performance indicators. FT examination process is to analyze variance by ranks. This is used in cases where there is no desire to build strong distributional assumptions [61].

2.4.3. Factor Analysis (FA). FA is a statistical method to model the covariation among a set of data, which is applied to determine the most effective variables when the number of variables is high and the relationships between them are unknown. The main purpose of FA is to decrease the dimensionality of a series of variables and determine the most important variables affecting phenomena production. FA is generally divided into two classes, namely, Exploratory Factor Analysis (EFA) and Confirmatory Factor Analysis (CFA). EFA was applied in this research, which explores the latent constructs when the structure of the relationships among variables is unknown [62]. In this study, because the size of the sample is a determining factor in the accuracy of element clustering by FA, it must be assured that it is adequate. So Kaiser-Mayer-Olkin (KMO) and Bartlett's test of sphericity were applied to check the suitability of data.

2.4.4. Multiple Logistic Regression. Regression analysis is a statistical method to exploit independent variables and model the relationship between dependent and independent variables $[63,64]$. The logistic regression model is an improved regression applied for dichotomous dependent variables. In this situation, binary logistic regression is utilized. Consider $t$ as a linear function of the independent variables, in which $\beta=\left(\beta_{0}, \beta_{1}, \ldots, \beta_{m}\right)$ is the regression coefficient for $x=\left(x_{1}, x_{2}, \ldots, x_{m}\right)$ independent variables and $\varepsilon$ is the error [65]:

$$
t=\beta_{0}+\beta_{1} x_{1}+\cdots+\beta_{M} x_{M}+\varepsilon,
$$

The impute values are from negative infinity to positive infinity, while $t$ must be between 0 and 1 . The logistic function can solve this problem that is defined as equation (2), which has values of 0 to 1 and is interpreted as a probability:

$$
\sigma(t)=\frac{e^{t}}{e^{t}+1}=\frac{1}{1+e^{-t}}
$$

The binary logistic model will be in the form of equation (3) that presents the probability of the dependent variable: 


$$
F(x)=\frac{1}{1+e^{-\left(\beta_{0}+\beta_{1} x+\cdots+\beta_{M} x_{M}\right)}} .
$$

As $\beta_{i}$ increases positively, $\sigma(t)$ approaches 1 , indicating the success probability increments [66].

2.4.5. Artificial Neural Network (ANN). Neural networks $(\mathrm{NN})$, or more accurately artificial neural networks, are physically cellular systems able to achieve, store, and use experimental data $[67,68]$. NNs, with their extraordinary ability to derive a general solution from imprecise or complicated data, are applied for extracting patterns and detecting trends that are too complex to be observed by human, expert systems, or other computer methods [69-77].

Network learning intelligent models have advantages over other methods such as flexibility over data, free assumptions in methodology, no requirement for professional statistical analysis before modeling, and can easily model complex multiparameter systems. This method can be very useful in finding complex nonlinear relationships when the database is high dimensional $[47,78-81]$. Obtaining more efficient models to predict accidents will allow researchers to achieve a better performance in road safety. Network learning intelligent models help them to identify patterns in identifying problems and influential parameters in accidents. The advantage of intelligent models over statistical methods is that in intelligent models, the weight of variables and the amount of effect can be calculated, and the resulting network can be optimized while in statistical methods, it is not possible to optimize the model and obtain the influence of parameters concurrently [82-86].

One of the various types of network learning intelligent models is ANN. The main purpose of developing ANN models is to explore the impact of each independent variable on the goal variable. The reason for emphasizing intelligent models in this research is the high efficiency compared to other methods and determining the amount and importance of the parameters influencing the pedestrian accidents $[87,88]$.

Multilayer Perceptron (MLP) and Radius Basis Function $(\mathrm{RBF})$ are applied in this research, among different methods of ANN models, and finally, the modeling results are compared. A general distinction between these two methods is that $\mathrm{RBF}$ is a localist learning kind that is responsive just to a limited section of input space, while MLP is a further distributed technique [89]. The performance of MLP and $\mathrm{RBF}$ is completed in two stages; the first phase is the training phase, which determines the weight of NN neurons and applies a set of patterns for training the network, and the second phase is the testing phase, which represents a list of testing patterns to the trained network to find the network output produced and compare the trained network outputs with the desired output of the testing patterns. It determines the classification accuracy of the network [29, 90, 91].

MLP and RBF models consist of neurons that are defined in three layers of input, hidden, and output. The inputs as the original predictors or the hidden layers comprise a group of variables, and the output layer includes the responses. Each variable in a layer is named a node. A node takes a changed linear combination of the outputs from the nodes beneath the layer. Then, as an output, it sends a conversion of itself as one of the inputs to one or more nodes on the subsequent layer. Typically, the conversion functions are named activation functions. There are different forms of activation functions that are applied by the nature of the problem and are selected by the network architecture. The number of neurons in input and output layers depends on independent and dependent variables, respectively. The number of neurons in the hidden layers was also specified by calibration in several runs [92, 93].

\section{Results}

3.1. Frequency Analysis. Analysis of pedestrian accidents based on the color of pedestrian clothing, as shown in Figure 1(a), showed that female pedestrians wore darker clothing than males $(64.7 \%$ of female pedestrians had dark clothing and only $31.7 \%$ of male pedestrians had dark clothing). Frequency results showed a higher proportion of female pedestrian accidents with dark clothing (such as chador clothing) than bright clothing. Figure 1(b) also shows that among female pedestrians with dark clothing, 57.1\% were females with chador clothing and $42.9 \%$ of them wore other dark clothing.

Figure 2 shows that $30.8 \%$ of female pedestrians accounting for the highest percentage of accidents were aged 51 and above, that $73.6 \%$ of them had dark clothing, and $25.8 \%$ of female pedestrians were aged 30 or less, of which only $24.1 \%$ had dark clothing, indicating that most females in the older age group tended to wear darker clothing than younger females aged 30 or less. Due to the slower walking speed and old age, more accidents had resulted, while the younger female pedestrians were more inclined to wearing bright clothing, which can reduce the occurrence of accidents, especially at night.

According to Figure 3(a), 77.9\% of female accidents with dark clothing occurred at night or sunset, of which $44.7 \%$ occurred between $5 \mathrm{pm}$ and $9 \mathrm{pm}, 26.5 \%$ occurred between 9 pm and $1 \mathrm{am}$, and $6.7 \%$ happened between 1 am and 7 am. On the other hand, $62.8 \%$ of female pedestrian accidents with dark clothing (as the highest accident rate) occurred in rainy weather conditions and the least accidents (10.8\%) occurred in clear weather (sunny or moonlit), as shown in Figure 3(b). It shows that in rainy weather conditions, the possibility of female pedestrian accidents with dark clothing was much greater because of insufficient visibility of drivers. Also, according to the results of analysis and Figure 3(c), $43.7 \%$ of accidents occurred on arterial roads, indicating that the probability of the occurrence of accidents was more due to a higher speed of vehicles and the presence of more females on these roads and lower resolution of dark clothing.

According to Figure 4, 58.2\% of female accidents with dark clothing occurred on Wednesday to Friday and holidays (on recreational trips), and only $41.8 \%$ of accidents occurred on Saturday to Wednesday, indicating that due to more work trips, $41.5 \%$ and $36.7 \%$ of accidents were on arterial roads and highways, respectively, and only $21.8 \%$ occurred on access roads. 
TABLE 1: Types of variables in the research.

\begin{tabular}{|c|c|c|}
\hline Number & Variables & Parameters \\
\hline \multicolumn{3}{|c|}{ Dependent variable } \\
\hline 1 & Accident severity & $\begin{array}{l}\text { (1) Injury } \\
\text { (2) Fatal }\end{array}$ \\
\hline \multicolumn{3}{|c|}{ Independent variables } \\
\hline 1 & Clothing color & $\begin{array}{l}\text { (1) Bright clothing } \\
\text { (2) Chador clothing } \\
\text { (3) Other dark clothing }\end{array}$ \\
\hline 2 & Age & $\begin{array}{l}\text { (1) Less than or equal to } 30 \\
\text { (2) } 31 \text { to } 40 \\
\text { (3) } 41 \text { to } 50 \\
\text { (4) } 51 \text { and over }\end{array}$ \\
\hline 3 & Accident time & $\begin{array}{l}\text { (1) } 7: 00 \text { to } 13: 00 \\
\text { (2) } 13: 00 \text { to } 17: 00 \\
\text { (3) } 17: 00 \text { to } 21: 00 \\
\text { (4) } 21: 00 \text { to } 1: 00 \\
\text { (5) } 1: 00 \text { to } 7: 00\end{array}$ \\
\hline 4 & Day & $\begin{array}{l}\text { (1) Saturday to Wednesday } \\
\text { (2)Wednesday to Friday and holidays }\end{array}$ \\
\hline 5 & Weather condition & $\begin{array}{l}\text { (1) Clear } \\
\text { (2) Rainy } \\
\text { (3) Cloudy }\end{array}$ \\
\hline 6 & Education & $\begin{array}{l}\text { (1) Illiterate } \\
\text { (2) Just reading and writing } \\
\text { (3) Primary school } \\
\text { (4) High school } \\
\text { (5) Diploma } \\
\text { (6) Associate's degree } \\
\text { (7) Bachelor's degree } \\
\text { (8) Master's degree } \\
\text { (9) Doctoral degree }\end{array}$ \\
\hline 7 & Pedestrian action & $\begin{array}{l}\text { (1) Crossing from the authorized location } \\
\text { (2) Crossing from the unauthorized direction } \\
\text { (3) Standing alongside the road } \\
\text { (4) Getting out of the vehicle } \\
\text { (5) Walking in the direction of the vehicle's movement } \\
\text { (6) Walking in the nondirection of the vehicle's movement } \\
\text { (7) Out of the roadway } \\
\text { (8) Working on the vehicle } \\
\text { (9) Sudden jump in front of the vehicle } \\
\text { (10) Sudden running on the roadway } \\
\text { (11) Pushing the vehicle } \\
\text { (12) Crossing the road barriers } \\
\text { (13) Others }\end{array}$ \\
\hline 8 & Crossing facilities & $\begin{array}{l}\text { (1) Pedestrian bridge } \\
\text { (2) Underpass } \\
\text { (3) Crosswalk } \\
\text { (4) Don't have }\end{array}$ \\
\hline 9 & Crossing permit & $\begin{array}{l}\text { (1) Allowed } \\
\text { (2) Illegal }\end{array}$ \\
\hline 10 & Job & $\begin{array}{l}\text { (1) Student } \\
\text { (2) College students } \\
\text { (3) Self-employed } \\
\text { (4) Clerk } \\
\text { (5) Housewife }\end{array}$ \\
\hline 11 & Road classification & $\begin{array}{l}\text { (1) Highway } \\
\text { (2) Arterial road } \\
\text { (3) Access road }\end{array}$ \\
\hline 12 & Fault status & $\begin{array}{l}\text { (1) Guilty } \\
\text { (2) Nonguilty }\end{array}$ \\
\hline
\end{tabular}




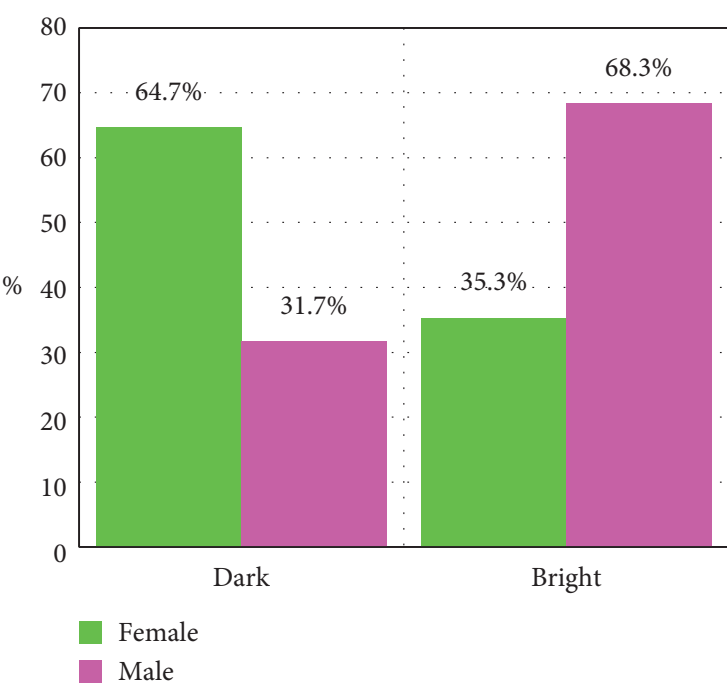

(a)

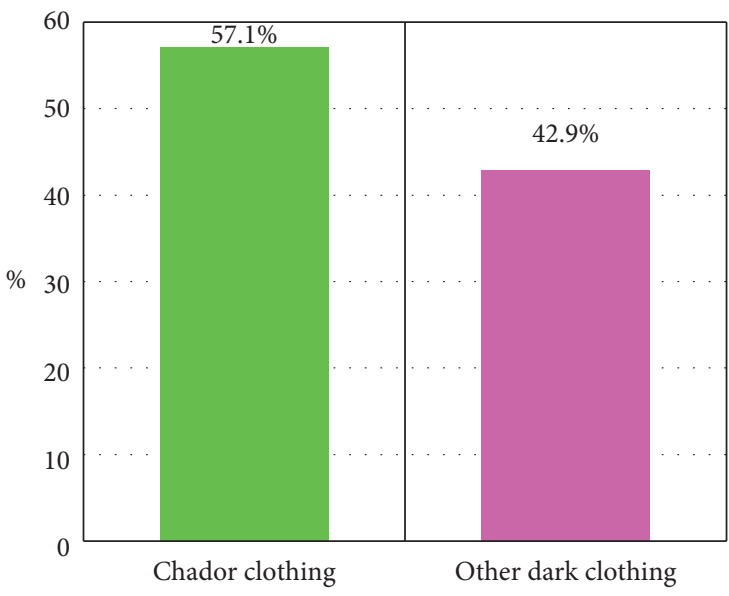

(b)

Figure 1: Pedestrian accident statistics based on: (a) pedestrians' clothing color, (b) dark clothing.

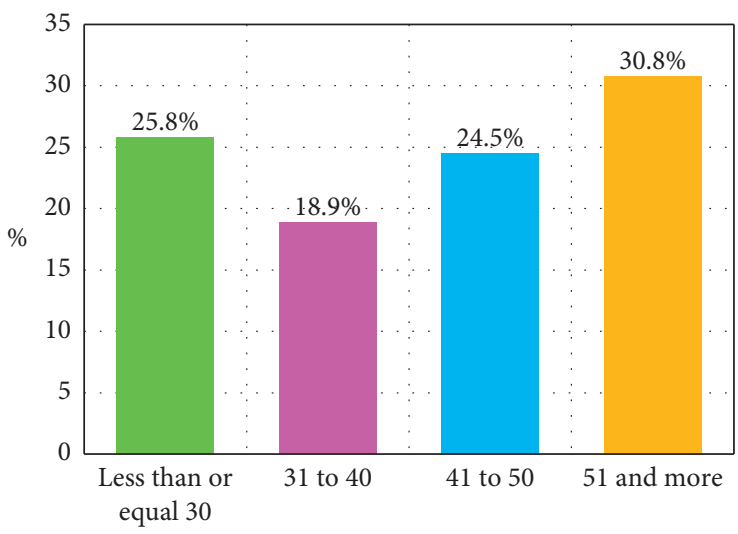

(a)

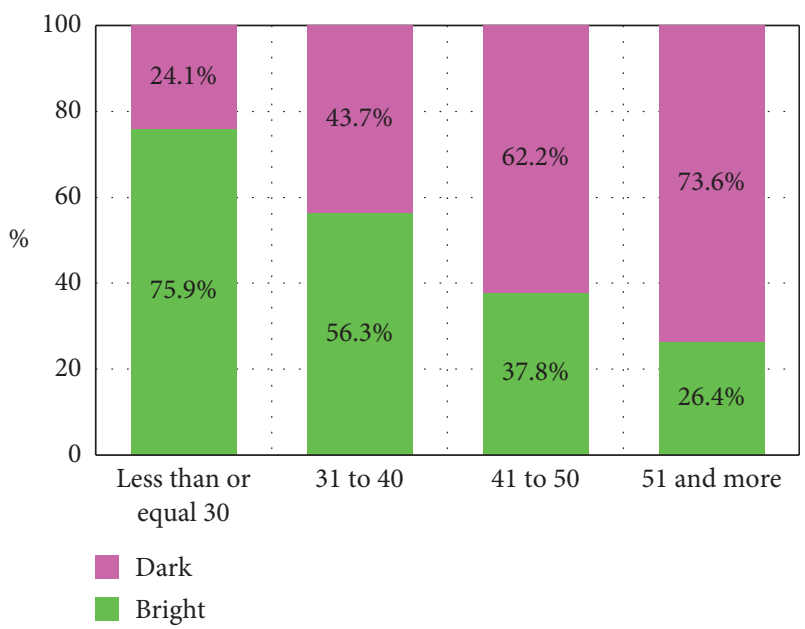

(b)

FIgURE 2: Female pedestrian accident statistics based on (a) age and (b) age and clothing color.

As shown in Figure 5(a), female pedestrians with dark clothing with a diploma had the highest accident rate (23.5\%) and pedestrians with a doctorate had the lowest accident rate $(0.3 \%)$, indicating lower awareness at the lower level of education with regard to being more cautious, and this is validated as the highest percentage of accidents occurred in the age group of 51 and above. Also, according to Figure 5(b), 34.9\% of accidents involved housewives, accounting for the highest accident rate, indicating that most female pedestrians with dark clothing were housewives, and clerks had the lowest accident rates (13.8\%), which indicates that they paid more attention to their surroundings.

According to Figure 6, 17.7\% of female pedestrians crossed at the authorized locations, indicating that female pedestrians with dark clothing who used the allowed passages (68.2\% of accidents) had more accident rates.

Also, as illustrated in Figure 7, 41.6\% of female pedestrian accidents with dark clothing, the highest accident rate, occurred where there was a pedestrian bridge (Figure 7(a)), indicating that there were appropriate facilities for crossing. Also, the highest number of female pedestrian accidents occurred among those aged 51 and above, who preferred to cross the road due to difficulty in climbing the stairs of the pedestrian bridge. The lowest accident rate based on crossing facilities $(6.7 \%)$ occurred where there was an underpass, indicating that the underpass had a decreasing effect on the severity of accidents. However, according to Figure 7(b), 62.9\% of accidents were nonguilty pedestrians. 


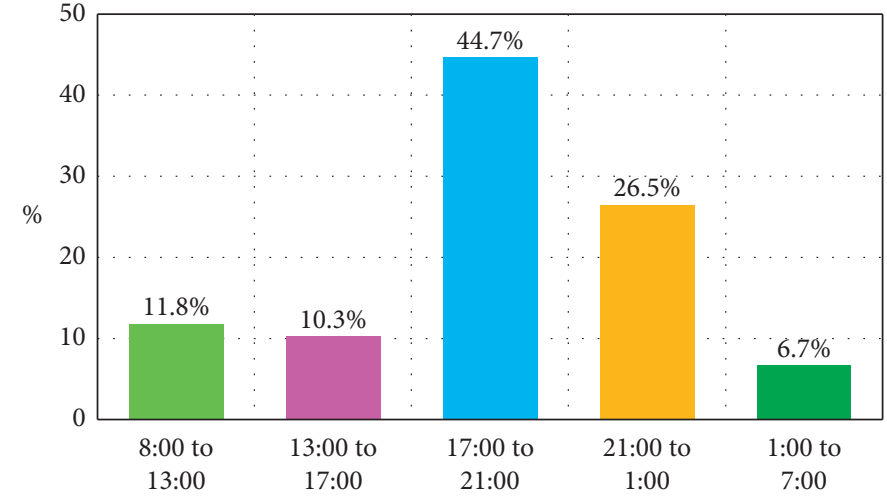

(a)

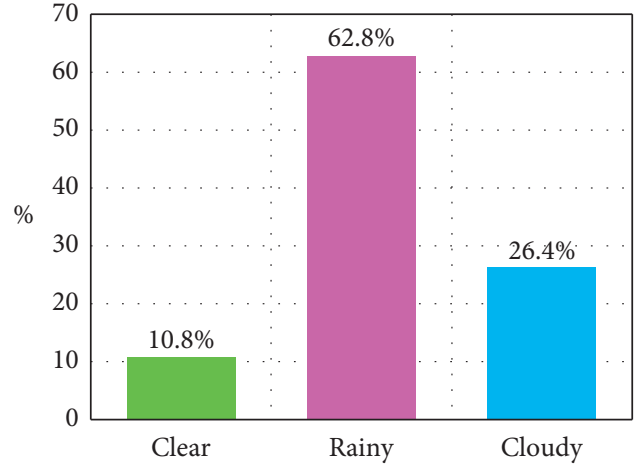

(b)

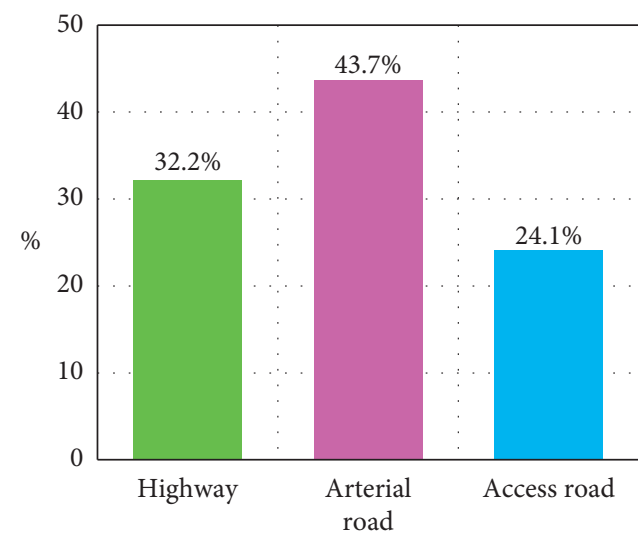

(c)

FIgURE 3: Female pedestrian accident statistics with dark clothing based on (a) accident time, (b) weather condition, and (c) road classification.

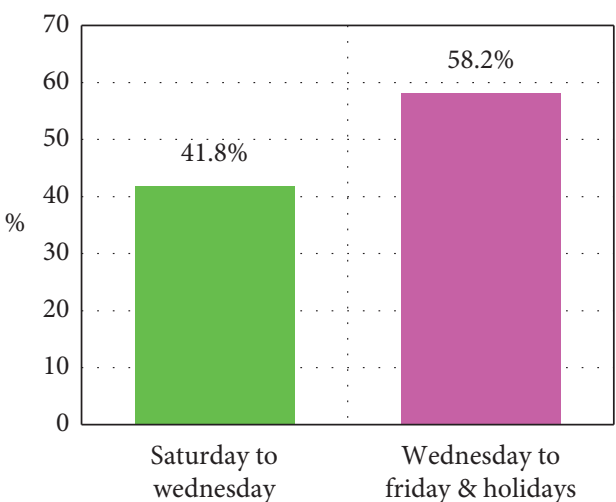

(a)

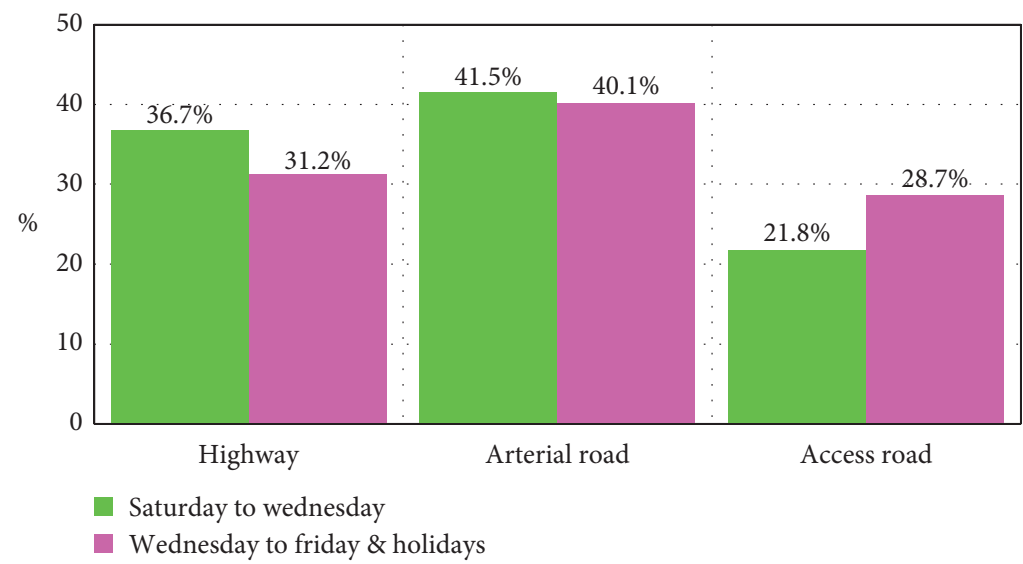

(b)

FiguRE 4: Female pedestrian accident statistics with dark clothing based on: (a) day, (b) road classification and day.

3.2. K-S Test Results. In order to evaluate the normality of data, the statistical distribution of data should be ensured, and the K-S test was applied to check the normality of distribution. Table 2 indicates the results of this test for dimensions.
As Table 2 indicates, the significance level in the $\mathrm{K}-\mathrm{S}$ test was less than 0.05 , and considering the $5 \%$ error, the null hypothesis $\left(H_{0}\right)$ was rejected. So, the distribution was not normal and nonparametric tests were applied in this research. 


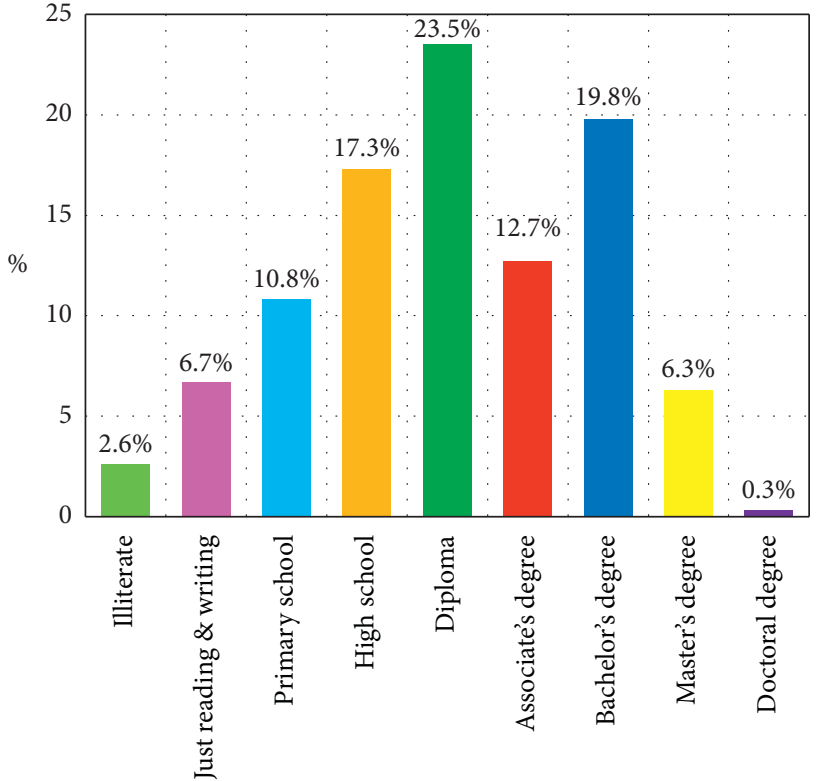

(a)

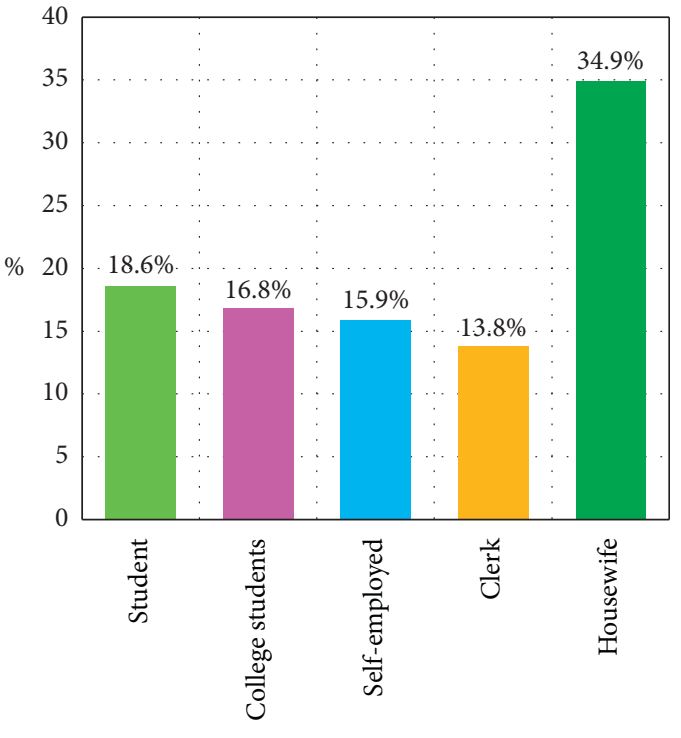

(b)

Figure 5: Female pedestrian accident statistics with dark clothing based on: (a) education, (b) job.

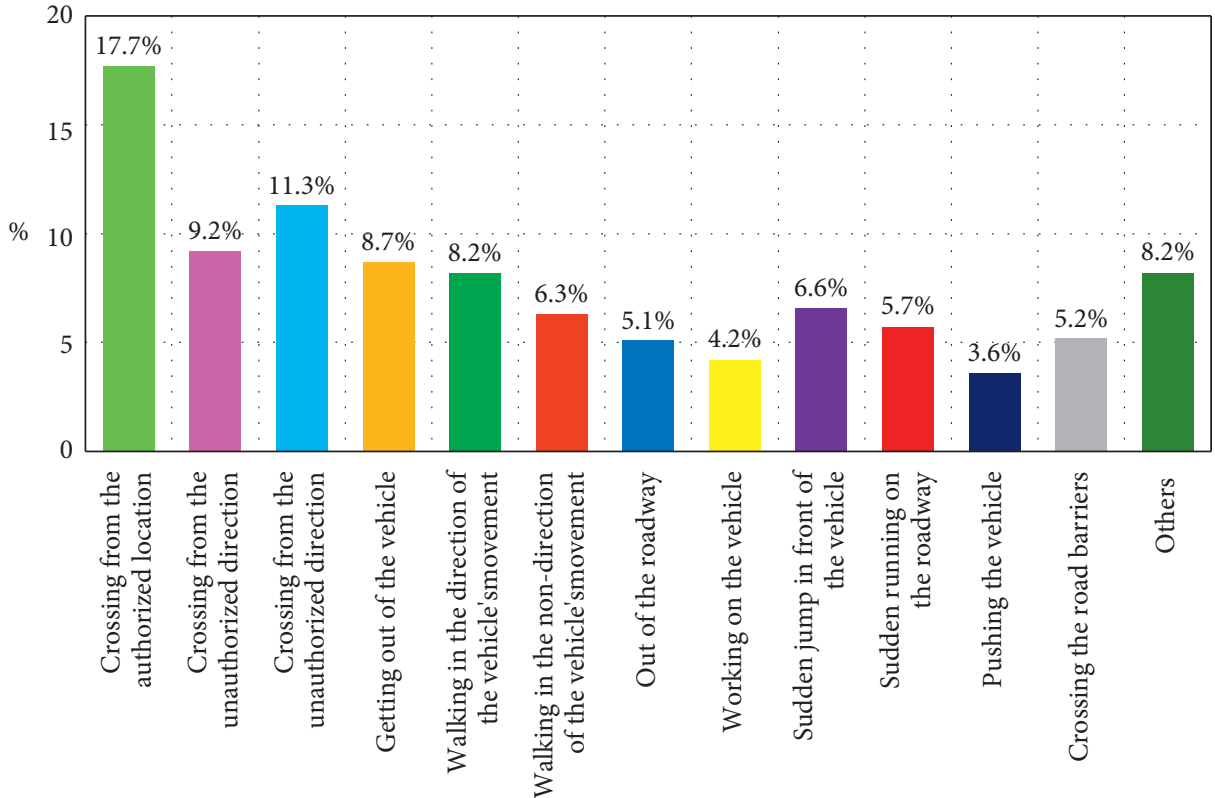

(a)

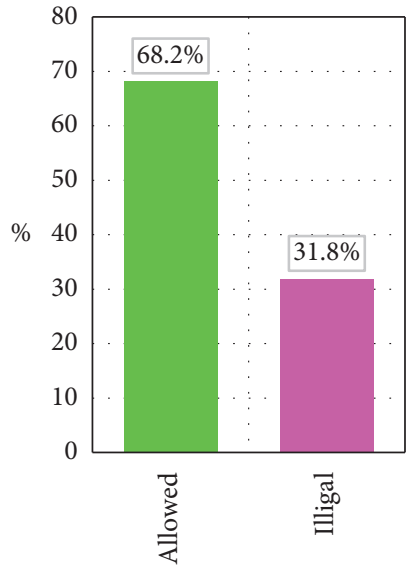

(b)

Figure 6: Female pedestrian accident statistics with dark clothing based on: (a) pedestrian action, (b) crossing permit.

3.3. FT Results. There were 12 independent variables in this study, the rank of which was examined by FT. Table 3 illustrates the statistical significance in which the sample volume, chi-square statistic, degrees of freedom, and significance level are presented.

As illustrated in Table 3, the significance level of less than $5 \%$ indicated that $\mathrm{H}_{0}$ was rejected. Therefore, ratings were not uniform. In Table 4, the ranking of independent variables is presented. The smaller the mean rates, the higher the importance of the variable.

According to Table 4, the variables of clothing color, weather condition, and age had the highest rank, with the scores of 4.71, 5.82, and 6.05, respectively. On the other hand, the variables of job, day, and fault status were the least important factors in the occurrence of accidents. Results indicated that clothing color as a human factor had the 


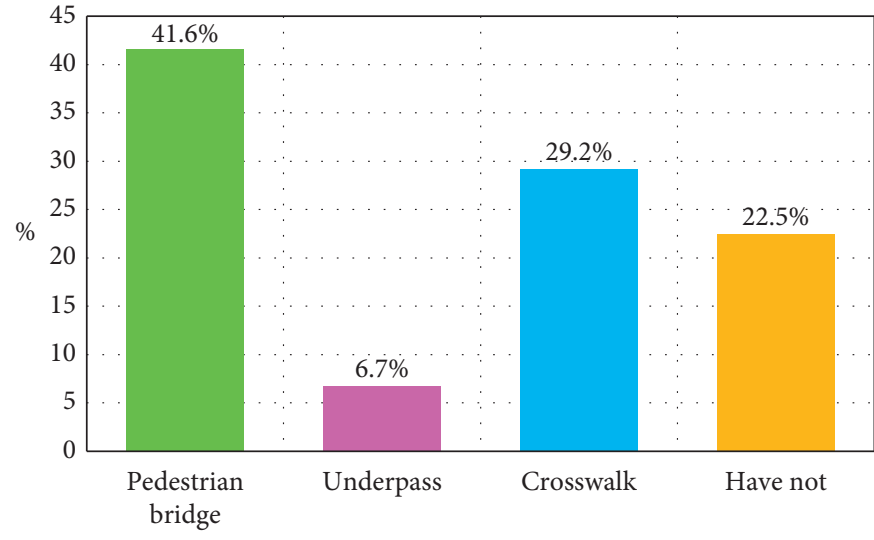

(a)

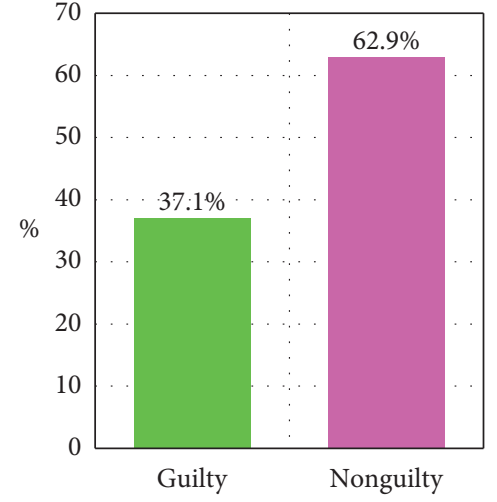

(b)

FiguRE 7: Female pedestrian accident statistics with dark clothing based on: (a) crossing facilities, (b) fault status.

TABLE 2: K-S test results.

\begin{tabular}{lcccccc}
\hline \multirow{2}{*}{ Number } & Variables & \multicolumn{3}{c}{ Most extreme differences } & \multirow{2}{*}{ Test statistic } & Asymp. Sig. (2-Tailed) \\
\hline 1 & Clothing color & 0.524 & 0.524 & -0.356 & 0.524 & 0.0 \\
2 & Age & 0.472 & 0.472 & -0.410 & 0.472 & 0.0 \\
3 & Accident time & 0.177 & 0.143 & -0.177 & 0.177 & 0.0 \\
4 & Day & 0.378 & 0.378 & -0.305 & 0.378 & 0.0 \\
5 & Weather condition & 0.425 & 0.425 & -0.357 & 0.425 & 0.0 \\
6 & Education & 0.254 & 0.174 & -0.254 & 0.254 & 0.0 \\
7 & Pedestrian action & 0.387 & 0.387 & -0.304 & 0.387 & 0.0 \\
8 & Crossing facilities & 0.184 & 0.184 & -0.172 & 0.184 & 0.0 \\
9 & Crossing permit & 0.324 & 0.324 & -0.356 & 0.324 & 0.0 \\
10 & Job & 0.171 & 0.144 & -0.171 & 0.171 & 0.0 \\
11 & Road classification & 0.398 & 0.285 & -0.398 & 0.398 & 0.0 \\
12 & Fault status & 0.230 & 0.251 & -0.230 & 0.230 & 0.0 \\
\hline
\end{tabular}

TABLE 3: FT results.

\begin{tabular}{lccc}
\hline Number of data & Chi-square & Degrees of freedom & Asymp. Sig. \\
\hline 6128 & 31458.703 & 11 & 0.0 \\
\hline
\end{tabular}

greatest impact on the occurrence of female pedestrian accidents, followed by weather condition, which was illustrated as an environmental factor and the second most effective factor in increasing the occurrence of accidents. Age was identified as the third most influential factor in accidents.

3.4. FA Results. Table 5 illustrates the results of FA, indicating the KMO index and the Bartlett's test.

As indicated in previous studies, the closer the KMO index value is to one, the better the desired data for factor analysis. According to Table 4, the KMO index value was close to 0.60 , indicating that it was appropriate to use FA. Moreover, similar results have been presented in previous studies [94]. Also, the significance level of the test statistic was less than 0.05 , meaning that there was a significant correlation between the variables.
Table 6 indicates the eigenvalues and variance corresponding to each component. Whenever the eigenvalue of a component is higher, that component indicates more variance. In Table 6, initial eigenvalues, and eigenvalues of nonrotating and post-rotating extraction components are presented. Results indicated that the components 1 to 5 had eigenvalues greater than 1 . So, they remained in the analysis.

Table 7 indicates the matrix of the remaining components. The values in Table 7 illustrate the correlation of each variable with the relevant components.

The higher the absolute value of the coefficients, the more effective the component was in the total changes of each variable [94]. FA was performed on 12 independent variables affecting female pedestrian accidents, which identified five main factors. The analysis showed that the variables of clothing color and weather condition were under the first component that the significant coefficients between the first component and each variable were 0.856 and 0.839 
TABLE 4: Mean rank in FT.

\begin{tabular}{lcc}
\hline Variables & Mean & Rank \\
\hline Clothing color & 4.71 & 1 \\
Weather condition & 5.82 & 2 \\
Age & 6.05 & 3 \\
Accident time & 6.56 & 4 \\
Road classification & 7.53 & 5 \\
Pedestrian action & 7.87 & 6 \\
Education & 7.99 & 7 \\
Crossing permit & 8.15 & 8 \\
Crossing facilities & 9.01 & 9 \\
Job & 10.15 & 10 \\
Day & 10.63 & 11 \\
Fault status & 11.07 & 12 \\
\hline
\end{tabular}

TABle 5: KMO and Bartlett's test.

\begin{tabular}{lccc}
\hline \multirow{2}{*}{ KMO measure of sampling adequacy } & \multicolumn{2}{c}{ Bartlett's test of sphericity } & Df \\
& Approximate Chi-square & 66 & Sig. \\
\hline 0.593 & 6153.749 & 0.0 \\
\hline
\end{tabular}

and positive, respectively. Therefore, it can be said that clothing color and weather condition were the primary factors in the occurrence of female pedestrian accidents. Also, education, accident time, and age constituted the second most influential components in accidents. Accident time and age (with the coefficients of 0.728 and 0.596 , respectively) positively affected the occurrence of accidents, and education (with a coefficient of -0.798 ) had a significant impact on reducing accidents. Similarly, road classification and pedestrian action variables constituted the third component (with coefficients of 0.737 and 0.612 , respectively); day, crossing facilities, and job (with coefficients of 0.774 , -0.607 , and -0.528 , respectively) constituted the fourth component; and crossing permit and fault status (with coefficients of -0.648 and 0.662 , respectively) constituted the fifth most effective factors in female pedestrian accidents.

3.5. MLR Results. A binary model was required, as there were just two possible outcomes, namely, injury or fatal severity of accidents. For MLR modeling of the severity of female pedestrian accidents, 2 dependent variables and 55 independent sub-variables were defined and then modeled. Table 8 presents a summary of three methods of entering, forward stepwise, and backward stepwise in the MLR model.

According to Table 8, in the entering method, as all the variables entered the equation at the same time, the model did not have the opportunity to process the data properly, and therefore it was not a suitable method. So, the forward and backward stepwise methods were used. Table 8 includes two criteria for the correct percentage and goodness of fit of the model. The goodness of fit $(0.648)$ and the correct percentage $(86.3 \%)$ of the backward method were higher than the other two methods, so this method was used for the logistic model. In Table 9, the chi-square statistic, degree of freedom, and significance level of test statistic in step 20 are presented.
Results of Table 9 indicated that the amount of chisquare statistic was 1828.200 . Also, the significance level of the model was less than 0.05 , indicating the suitability of the fit of the MLR model. Table 10 illustrates the accuracy of the model in predicting accident severity and is used for evaluating the performance of the prediction model and, in other words, the accuracy of accident severity classification.

Table 10 indicates that out of 5268 injury accidents, 5034 cases and out of 860 fatal accidents, 252 cases were predicted correctly by the model. The prediction accuracy of the MLR model was $95.6 \%$ for injury accidents and $29.3 \%$ for fatal accidents. So, the accuracy of the MLR model in the classification of injury accidents was more than fatal accidents. Also, the accuracy of the whole model in determining the severity of accidents was $86.3 \%$, meaning that with a confidence of $86.3 \%$, the MLR model was able to predict the severity of accidents.

In order to model the severity of accidents, 55 independent sub-variables were included in the MLR model and finally, 12 variables were determined as the effective parameters in accidents. In Table 11, the results of the model are represented for step 20 . Since the significance level was below $5 \%$, the null hypothesis was rejected and indicated the significance of the MNR model. When $\beta_{i}$ is positive, as variable $x_{i}$ increases, the accident probability will be raised. In contrast, if $\beta_{i}$ is negative, an increase in $x_{i}$ will decrease the accident probability [94, 95].

Results of Table 11 indicated that the variables of age 51 and above, chador clothing, other dark clothing, 17:00 to 21:00 accident time, Wednesday to Friday and holidays (nonworking days), sudden jump in front of the vehicle, rainy weather, and arterial road increased the probability of female pedestrian accidents. Moreover, the variables of $1: 00$ to 7:00 accident hours, master's degree, walking in the nondirection of the vehicle's movement, and allowed to cross reduced the likelihood of female pedestrian accidents. 
TABLE 6: Total variance explained.

\begin{tabular}{|c|c|c|c|c|c|c|c|c|c|}
\hline \multirow{2}{*}{ Components } & \multicolumn{3}{|c|}{ Initial eigenvalues } & \multicolumn{3}{|c|}{ Extraction sums of squared loadings } & \multicolumn{3}{|c|}{ Rotation sums of squared loadings } \\
\hline & Total & $\%$ of variance & Cumulative $\%$ & Total & $\%$ of variance & Cumulative \% & Total & $\%$ of variance & Cumulative \% \\
\hline 1 & 2.559 & 21.329 & 21.329 & 2.559 & 21.329 & 21.329 & 2.524 & 21.035 & 21.035 \\
\hline 2 & 1.659 & 13.828 & 35.157 & 1.659 & 13.828 & 35.157 & 1.616 & 13.466 & 34.500 \\
\hline 3 & 1.230 & 10.252 & 45.408 & 1.230 & 10.252 & 45.408 & 1.198 & 9.983 & 44.483 \\
\hline 4 & 1.114 & 9.281 & 54.689 & 1.114 & 9.281 & 54.689 & 1.155 & 9.621 & 54.104 \\
\hline 5 & 1.079 & 8.989 & 63.678 & 1.079 & 8.989 & 63.678 & 1.149 & 9.574 & 63.678 \\
\hline 6 & 0.988 & 8.232 & 71.910 & & & & & & \\
\hline 7 & 0.922 & 7.681 & 79.591 & & & & & & \\
\hline 8 & 0.806 & 6.719 & 86.310 & & & & & & \\
\hline 9 & 0.784 & 6.534 & 92.844 & & & & & & \\
\hline 10 & 0.402 & 3.347 & 96.191 & & & & & & \\
\hline 11 & 0.329 & 2.745 & 98.936 & & & & & & \\
\hline 12 & 0.128 & 1.064 & 100.000 & & & & & & \\
\hline
\end{tabular}

TABle 7: Component matrix.

\begin{tabular}{|c|c|c|c|c|c|}
\hline \multirow{2}{*}{ Variables } & \multicolumn{5}{|c|}{ Components } \\
\hline & 1 & 2 & 3 & 4 & 5 \\
\hline Clothing color & 0.856 & -0.055 & -0.068 & 0.073 & -0.038 \\
\hline Age & 0.165 & 0.596 & -0.028 & 0.240 & 0.359 \\
\hline Accident time & -0.045 & 0.728 & 0.061 & 0.036 & 0.006 \\
\hline Day & 0.013 & 0.143 & -0.041 & 0.774 & -0.027 \\
\hline Weather condition & 0.839 & -0.006 & 0.017 & -0.074 & -0.041 \\
\hline Education & 0.018 & -0.798 & 0.013 & -0.054 & 0.157 \\
\hline Pedestrian action & -0.036 & 0.078 & 0.612 & 0.048 & -0.341 \\
\hline Crossing facilities & 0.165 & 0.049 & 0.089 & -0.607 & 0.024 \\
\hline Crossing permit & -0.118 & -0.142 & 0.006 & 0.096 & -0.648 \\
\hline Job & 0.145 & 0.229 & -0.073 & -0.528 & 0.064 \\
\hline Road classification & 0.023 & -0.135 & 0.737 & -0.387 & -0.118 \\
\hline Fault status & 0.152 & 0.195 & -0.013 & -0.103 & -0.662 \\
\hline
\end{tabular}

One of the most important results of the MNR model was that the chador clothing had the greatest effect on increasing the probability of female pedestrian accidents, followed by other dark clothing. Therefore, bright clothing color had a direct effect on reducing female pedestrian accidents, which was more important at night and in rainy weather (due to reduced driver visibility), so rainy weather as the third variable had the greatest impact on increasing the accident rate. The model also showed that the interactive effect of the darkness of the air and the darkness of the female pedestrian clothing increased the likelihood of accidents. This increase can be attributed to the reduced visibility of the pedestrian by the driver, which increases the likelihood of the pedestrian being killed in an accident. This becomes more important in arterial roads (due to the higher speed of the vehicles and the presence of pedestrians more than the highways), which had an increasing impact on the occurrence of accidents. Another important result was that in rainy weather, especially between $5 \mathrm{pm}$ and $9 \mathrm{pm}$, female pedestrians aged 51 and above were more prone to accidents. Higher education levels also had a great impact on reducing female pedestrian accidents.

\subsection{ANN Results}

3.6.1. The MLP Model. The MLP was applied to construct a prediction model that predicts one or more dependent variables (targets). In this research, in order to segment the data randomly, the model was constructed with $70 \%$ training data, and its accuracy was evaluated based on the remaining $30 \%$. The number of input parameters to the model was 12 . The number of input layer neurons was 59, and the number of output layer neurons was 2. The automatic selection structure selected 10 neurons in the hidden layer. One hidden layer was used because it is known to have sufficient approximating power [96]. Table 12 indicates the correct percentage of each sample. The cells in the diagonal line in each case represent the correct predictions.

Table 12 shows that 3586 of 3703 accidents were correctly classified as injury accidents and 478 of 594 accidents were correctly predicted as fatal accidents. Moreover, in 94.6\% of cases, the training sample was correctly classified. So, the accuracy of the MLP model was $94.6 \%$. Also, crossentropy error in training and testing samples was 619.025 and 328.277 , respectively. 
TABLE 8: Summary of the three methods of entering, forward stepwise, and backward stepwise of the severity of accidents.

\begin{tabular}{lccc}
\hline Number & Logistic regression methods & Correct percentage & Goodness of fit $\left(R^{2}\right)$ \\
\hline 1 & Enter & 81.5 & 0.626 \\
2 & Forward stepwise & 83.4 & 0.517 \\
3 & Backward stepwise & 86.3 & 0.648 \\
\hline
\end{tabular}

TABLE 9: Backward stepwise model results.

\begin{tabular}{lcccc}
\hline & & Chi-square & Df & Sig. \\
\hline \multirow{3}{*}{ Step 20} & Step & 173.028 & 1 & 0.000 \\
& Block & 1828.200 & 29 & 0.000 \\
& Model & 1828.200 & 29 & 0.000 \\
\hline
\end{tabular}

TABLE 10: Classification table.

\begin{tabular}{|c|c|c|c|c|}
\hline \multirow{3}{*}{ Observed } & \multicolumn{4}{|c|}{ Predicted } \\
\hline & \multicolumn{2}{|c|}{ Accident severity } & \multirow{2}{*}{\multicolumn{2}{|c|}{ Correct percentage }} \\
\hline & Injury & Fatal & & \\
\hline \multirow{2}{*}{ Accident severity } & Injury & 5034 & 234 & 95.6 \\
\hline & Fatal & 608 & 252 & 29.3 \\
\hline Overall percentage & \multicolumn{4}{|c|}{86.3} \\
\hline
\end{tabular}

Figure 8 shows an intuitive representation of the sensitivity to specificity for all levels of classification and illustrates two curves for injury and fatal accidents. Since there were only two categories, the curves were symmetric to the $45^{\circ}$ line. The greater the curve inclined to up and left, the network power was more accurate in prediction [97].

In binary classification problems, the area under the curve (AUC) is commonly applied to examine the performance of a prediction model [98]. As the AUC is a portion of the unit square area, the AUC value is always between zero and one. The area under the diagonal line in the ROC curve is always 0.5. So, the AUC should be more than 0.5 [99]. According to Table 13, the probability of injury or fatal accidents was measured as 0.948 , and because $0.948>0.5$, the response from the model was positive.

Figure 9 shows the extent to which the predicted amounts of the network change with the change in the amounts of independent variables. Normalization of this significance was obtained by dividing the importance values by their largest value and is expressed as a percentage. In Figure 9, the variables of clothing color, weather condition, education, and accident time had the greatest effect on the severity of female pedestrian accidents, respectively. This model showed that clothing color had the greatest impact on female pedestrian accidents.

3.6.2. The RBF Model. In order to model the RBF method, $70 \%$ of data were used to train the network and $30 \%$ of data were used for testing. The number of input layer neurons was 60 , and the number of output layer neurons was 2 . The automatic selection structure placed 9 neurons in the hidden layer. Table 14 shows the accuracy of predicting injury and fatal accidents.

Results of Table 14 indicated that the RBF network worked correctly in $86 \%$ of the cases. This model was successful in recognizing accidents leading to injuries. Also, the sum of squared error in training and testing samples of this method were 371.608 and 175.846, respectively. Moreover, Figure 10 shows the ROC curve for injury and fatal accidents. The closer the curve to the northwest, the more accurate the prediction of injury or fatal accidents [99].

According to the results of the AUC values presented in Table 15, the probability of an accident resulting in injury or fatalilty was calculated as 0.866 , and since $0.866>0.5$, the response was positive by the model.

In Figure 11, the relative importance of each of the independent variables on the dependent variable is shown, which illustrates the extent to which these variables have an impact in predicting accidents. Figure 11 shows that the most influential variable on the severity of female pedestrian accidents in the RBF model was clothing color. Then, weather condition and accident time had the most effect on the prediction, respectively.

3.7. Comparison of Analysis and Modeling Methods Results. In this research, various methods were used to determine more accurately the variables affecting the severity of female pedestrian accidents. Each method investigated the effective variables by its specific algorithm. In FT, the variables of clothing color, weather condition, and age were ranked from the first to third rankings that caused accidents, respectively, while in FA, the variables of clothing color and weather condition were identified as the first effective components and education, accident time, and age were recognized as the second effective components in female pedestrian accidents. This indicates that in FT and FA, clothing color and weather condition were identified as the most important parameters affecting accidents.

Comparing the correct prediction percentage in the MLR and the ANN models, the results indicated that the 
TABLE 11: MLR results in the twentieth step.

\begin{tabular}{|c|c|c|c|c|c|}
\hline Variables & $\beta$ & S.E. & Wald & Sig. & $\operatorname{Exp}(\beta)$ \\
\hline Age 51 and above & 3.405 & 0.889 & 14.670 & 0.012 & 30.114 \\
\hline Chador clothing & 4.624 & 1.578 & 8.587 & 0.023 & 101.901 \\
\hline Other dark clothing & 4.125 & 1.287 & 10.273 & 0.003 & 61.868 \\
\hline $1: 00$ to $7: 00$ & -1.658 & 0.861 & 3.708 & 0.001 & 0.191 \\
\hline $17: 00$ to $21: 00$ & 3.074 & 1.026 & 8.977 & 0.025 & 21.628 \\
\hline Wednesday to Friday and holidays & 1.493 & 1.070 & 1.947 & 0.003 & 4.450 \\
\hline Master's degree & -2.786 & 0.757 & 13.545 & 0.000 & 0.062 \\
\hline Sudden jump in front of the vehicle & 3.603 & 1.116 & 10.423 & 0.000 & 36.708 \\
\hline Walking in the nondirection of the vehicle's movement & -2.261 & 0.880 & 6.601 & 0.001 & 0.104 \\
\hline Allowed to cross & -1.098 & 0.855 & 1.649 & 0.016 & 0.334 \\
\hline Rainy weather & 4.007 & 1.131 & 12.552 & 0.000 & 54.982 \\
\hline Arterial road & 2.867 & 0.779 & 13.545 & 0.000 & 17.584 \\
\hline Constant & 5.260 & 2.361 & 4.963 & 0.000 & 192.481 \\
\hline
\end{tabular}

TABle 12: Classification in the MLP model.

\begin{tabular}{lcccc}
\hline \multirow{2}{*}{ Sample } & Observed & & \multicolumn{2}{c}{ Predicted } \\
& & Injury & Fatal & Correct percentage \\
\hline \multirow{3}{*}{ Training } & Injury & 3586 & 117 & 96.8 \\
& Fatal & 116 & 478 & 80.5 \\
\hline \multirow{3}{*}{ Testing } & Overall percentage & $86.2 \%$ & $13.8 \%$ & 94.6 \\
& Injury & 1504 & 61 & 96.1 \\
& Fatal & 67 & 199 & 74.8 \\
\end{tabular}

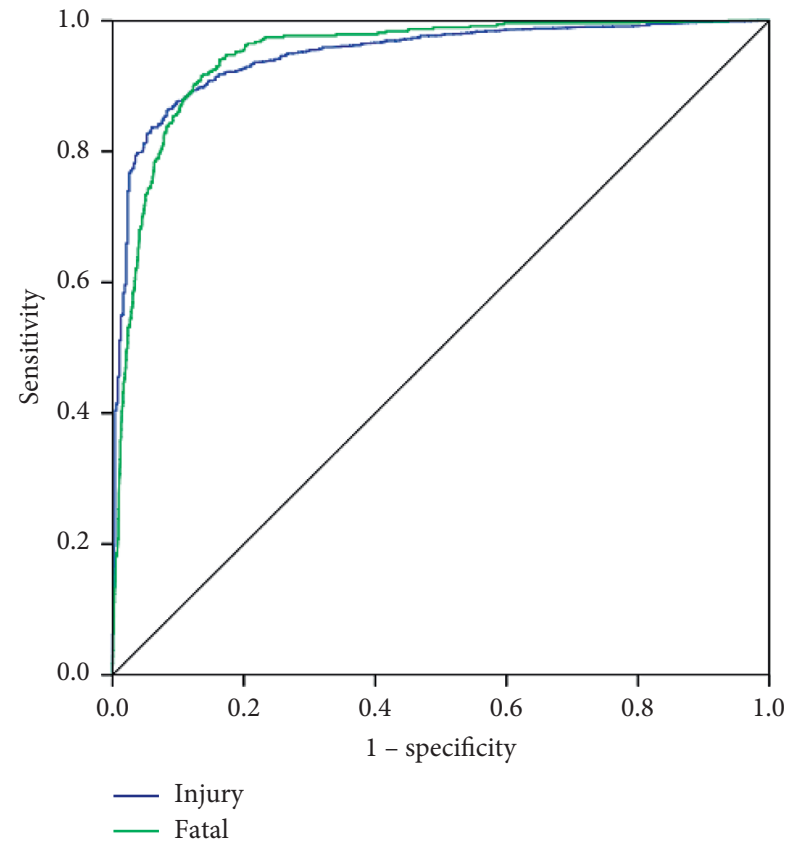

FIGURE 8: Receiver operating characteristic (ROC) curve of the MLP model.

TABLE 13: AUC for the MLP model.

\begin{tabular}{lcc}
\hline & & Area \\
\hline \multirow{2}{*}{ Accident severity } & Injury & 0.948 \\
& Fatal & 0.948 \\
\hline
\end{tabular}




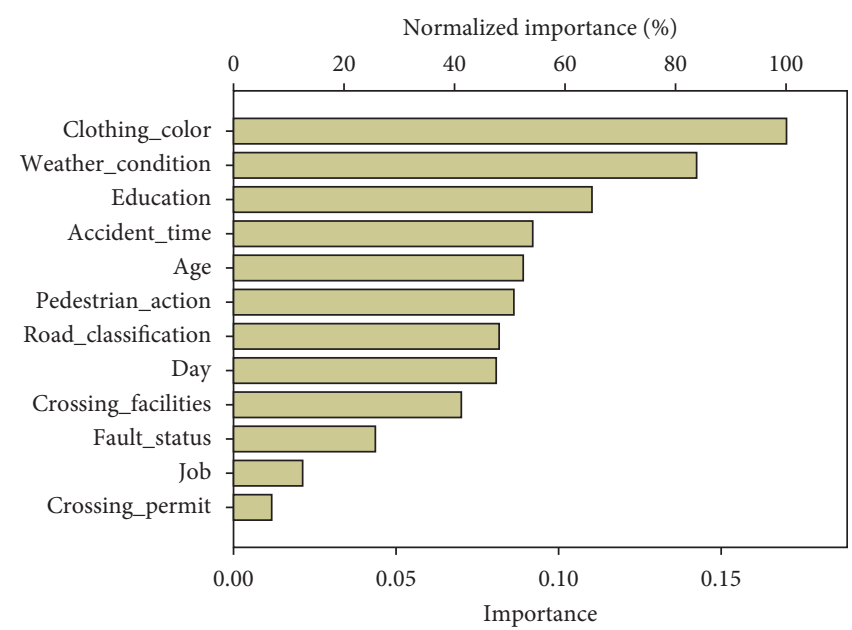

FIgURE 9: Independent variable importance in the MLP model.

TABLE 14: Classification in the RBF model.

\begin{tabular}{lcccc}
\hline \multirow{2}{*}{ Sample } & Observed & Predicted & Correct percentage (\%) \\
& & Injury & 101 & 97.3 \\
Training & Injury & 3631 & 103 & 16.9 \\
& Fatal & 506 & $4.7 \%$ & 86.0 \\
\hline \multirow{3}{*}{ Testing } & Overall percentage & $95.3 \%$ & 32 & 97.9 \\
& Injury & 1504 & 48 & 19.1 \\
& Fatal & 203 & $4.5 \%$ & 86.8 \\
\hline
\end{tabular}

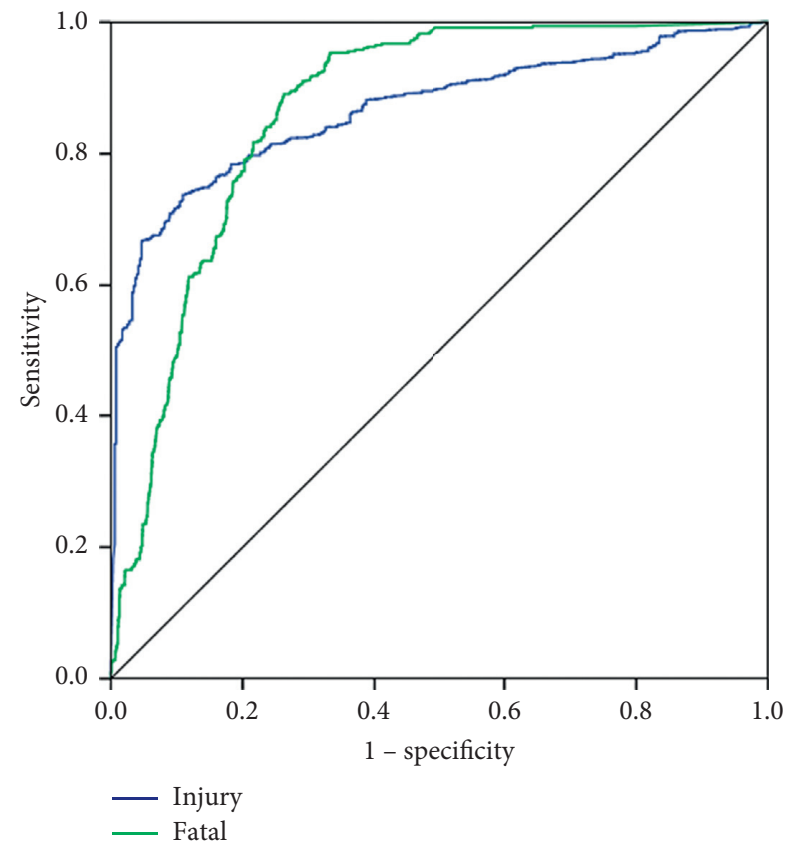

FIgURE 10: . TheROC curve of the RBF model.

MLP model performed better and had a higher prediction percentage than the rest. The prediction accuracy of the MLR model was $86.3 \%$, the prediction accuracy of the MLP model was $94.6 \%$, and the prediction accuracy of the RBF was $86.0 \%$. On the other hand, the prediction accuracy of the MLR model was more than RBF. The MLR model showed 
TABLE 15: The AUC for the RFB model.

\begin{tabular}{lrr}
\hline & & Area \\
\hline \multirow{2}{*}{ Accident severity } & Injury & 0.866 \\
& Fatal & 0.866 \\
\hline
\end{tabular}

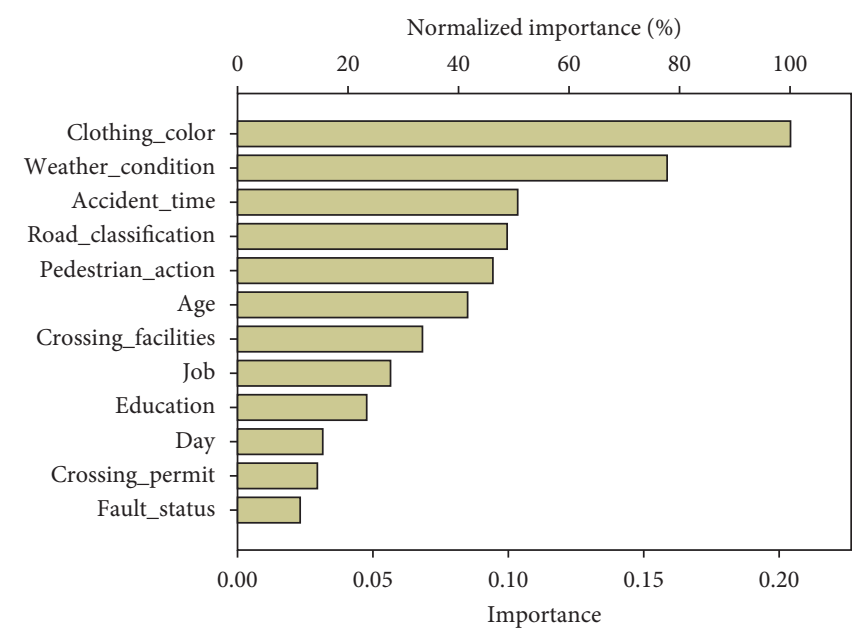

Figure 11: Independent variable importance in the RBF model.

that chador clothing and other dark clothing, respectively, had the greatest impact on increasing the probability of female pedestrian accidents, and then rainy weather had the highest effect on the occurrence of accidents. Higher education level also had a great impact on reducing accidents in the MLR model, while in the MLP model, due to better prediction, clothing color, weather condition, and education were the most effective factors in the occurrence of accidents. Also, in the RBF model, clothing color, weather condition, and accident time were the most effective factors. Consequently, clothing color and weather condition were the joint result of these three models of accident prediction as the most effective predictor.

The common point of analyses and models performed in this study was the clothing color of female pedestrians as the most important variable affecting the severity of accidents, especially at night. According to the MLR model, chador clothing and dark clothing color increased the probability of accident occurrence. In fact, the most dangerous situation for pedestrians was walking in the direction of the vehicle's movement at night, as it was very difficult for drivers to see a pedestrian at night. According to surveys conducted in this study, $64.7 \%$ of female pedestrians who were involved in an accident with vehicles at night had dark clothing.

The role of clothing color has also been highlighted in a previous study (Turner et al. [15]), which, different from this research, found that fluorescent red-orange-colored vests had the highest mean detection distance. But, in this research, bright clothing color had an important role in reducing the severity of accidents. This research showed that dark clothing color increased the severity of accidents. On the contrary, according to Clifton et al. [16], pedestrians with dark clothing had a lower rate of accidents. These findings may be due to the fact that the majority of accidents, almost $70 \%$, happened in the daytime, while in this research, about $22.1 \%$ of accidents occurred during daylight hours. But in compliance with Pour-Rouholamin and Zhou's [22] investigations, pedestrians not wearing contrasting clothing and pedestrians with dark clothing were more susceptible to accidents. On the other hand, in a study conducted in Iran by Besharati and Tavakoli Kashani [24], low light conditions and dark clothing of pedestrians were factors that increased the likelihood of accidents, which confirms the results of this study. So, according to Baireddy et al.'s [25] study, wearing contrasting or reflective clothing can reduce the occurrence of accidents and make pedestrians less prone to accidents, especially at night.

Various previous studies investigated the conspicuity of pedestrians that the results of the study confirm them [17-22]. The decreased ability of a driver to observe a pedestrian during nighttime is a contributing factor to many pedestrian accident types. This article is consistent with Tyrrell et al. [17], in which clothing color and pedestrian action influenced conspicuity, and pedestrians who wore black clothing, especially at night, reduced the conspicuity. According to Zegeer and Bushell [18] and Hefny et al. [21], similar to the results of this study, nighttime or low lighting conditions increased the risk of accidents. So pedestrians, especially in dark clothing, need to be more aware of the fact that they may be invisible to drivers when walking in the dark; thus, it is important for pedestrians to carry a flashlight or wear retro-reflective clothing/material or light-colored clothing at night. So, according to Fekety et al.'s [23] research, adding electroluminescent (EL) panels to pedestrian clothing will increase the conspicuity of pedestrians, and this is especially important for female pedestrians, especially for 
females with chador clothing at night, so chador clothing should be produced with retro-reflective materials or EL panels.

In accordance with Wood et al. [19] and Borzendowski et al.'s [20] study, pedestrian clothing had a significant impact to be recognized by drivers, especially at night, and wearing reflective clothing reduced the likelihood of accidents. Also, in accordance with previous studies of the visibility distance from the pedestrian (Wickramasinghe et al. [26]), results showed that wearing white clothing color was safer at nighttime while pedestrians wearing dark clothing color had lower visibility in the night.

The results of this study showed that $77.9 \%$ of female accidents with dark clothing occurred at night or sunset, which is in contrast to a research by Abdous and Mahmoudabadi [27] that showed that the vulnerability of female pedestrians at different times of the day is not significantly different, but the most important results of this study in common with Abdous and Mahmoudabadi's [27] results were that wearing chador clothing significantly increased their vulnerability.

\section{Conclusion and Future Directions}

The purpose of this study was to provide useful and practical solutions to improve the safety of female pedestrians using different statistical methods and intelligent models using police data collected from March 2017 to March 2019 to analyze the severity of female pedestrian accidents. The most important results can be mentioned:

(1) In general, female pedestrians had darker clothing than males, most of whom had chador clothing. Moreover, most of the female pedestrian accidents with dark clothing occurred between 17::00 and 21: :00 on Wednesday to Friday and holidays, especially on the arterial roads, and in the conditions of rainy weather. Most of these accidents occurred while crossing at authorized locations, and involved female pedestrians who had a diploma and were housewives. Most accidents occurred in the presence of pedestrian bridge facilities, which indicates there were appropriate facilities for crossing the pedestrians. On the other hand, most of the female pedestrians involved were nonguilty and aged 51 and above.

(2) Based on FT, the most important factors affecting female pedestrian accidents were identified as clothing color, weather condition, and age, indicating that the most influential factor in female pedestrian accidents was clothing color as a human factor and the second most important factor was weather condition as an environmental factor affecting the occurrence of accidents.

(3) FA results showed that the variables of clothing color and weather condition constituted the first component, indicating that these two variables were the most effective factors in the occurrence of female pedestrian accidents that had a large impact (due to the coefficient value) on the occurrence of accidents. Education, accident time, and age were also known to be the second influencing component on accidents, in which accident time and age positively and increasingly affected the occurrence of accidents, and education level had a significant effect on reducing accidents. Likewise, the variables of road classification and pedestrian action constituted the third component, day of the accident, crossing facilities, and job were constituted the fourth component, and, ultimately, fault status and crossing permit constituted the fifth effective component in female pedestrian accidents. According to the results of this analysis, the most effective factor in reducing the incidence of accidents was education. The most important result of FA was that clothing color had a significant effect on increasing the incidence of accidents. Due to the high percentage of female pedestrians with dark clothing (64.7\%), they had the highest accident rate, especially at night.

(4) In the MLR model, the effect of independent variables on the severity of accidents was investigated and the results showed that the accuracy of the model in predicting accidents in the backward stepwise method was $86.3 \%$. According to the results, wearing dark clothing was an important factor in increasing accidents. Females in Iran, due to wearing a veil and the tendency to wear dark clothing (chador and other dark clothing), have a significant influence on the incidence of accidents. As illustrated in this study, it is especially critical at $17: 00$ to $21: 00$ because of less clear clothing. Traffic reached its peak between 17::00 and 21::00, indicating an increase in traffic accidents' rate due to the increased number of vehicles, especially on the arterial roads and highways, and the presence of more pedestrians across the city. Females aged 51 and above were more likely to be involved in accidents due to a lower walking speed and, more importantly, dark clothing (73.6\% of females were 51 years and older). In rainy weather, the risk of pedestrian accidents was increased due to the reduced visibility of the pedestrian by the driver relative to the environment and the difficulty in controlling the vehicle when exposed to danger, especially at higher speeds. Whereas in clear weather conditions, the driver's view from the environment was greater and the likelihood of an accident was reduced. The results of accidents related to a sudden jump in front of the vehicle indicated that the severity of pedestrian accidents was directly related to the personality characteristics of pedestrians in addition to environmental and road conditions. In arterial roads, because of the higher speed of vehicles 
and the presence of more females on these roads and lower resolution of dark clothing than other roads, pedestrians were more likely to be involved in an accident. Accidents were reduced between $1:: 00$ and $7:$ :00 due to less vehicle attendance. One of the most important results in this model was that the chador clothing and other dark clothing had the most impact on increasing the probability of female pedestrian accidents, and rainy weather had the most impact on increasing the accident rate. Higher level of education also had a great impact on reducing pedestrian accidents. Therefore, bright clothing color had a direct impact on reducing accidents. This made more sense at night and in rainy weather (due to reduced driver visibility).

(5) In the ANN models, the results of the methods used showed that the MLP was more accurate than the $\mathrm{RBF}$, indicating that the MLP model was better at predicting the severity of accidents. Sensitivity analysis of the two methods showed that the MLP had more power to predict and estimate accidents than the RBF. In the MLP model, the variables of clothing color, weather condition, education, and accident time had the most impact on the severity of accidents, while in the RBF model, the variables of clothing color, weather condition, accident time, and road classification had the highest impact, respectively. But in general, the ANN results in both models showed that the clothing color variable had the most effect on the prediction of female pedestrian accidents, and considering the MLR model, dark clothing color had the most influence on the occurrence of the accidents. Therefore, females who wore chador and other dark clothing were more prone to accidents, which necessitate the adoption of appropriate solutions.

(6) For future work and analysis, we will deal with some state-of-the-art machine learning and optimization algorithms to be incorporated with the proposed approach to attain more accuracy. Moreover, we can implement the deep learning approaches to reach a better prediction percentage.

\section{Safety Approach}

Based on the results of the analyses and models of the research, the following measures are suggested to reduce the probability of injury and fatal accidents of female pedestrians:

(1) Due to the high percentage of female pedestrian accidents with dark clothing color, increasing public awareness of the use of bright clothing color for female pedestrians is one of the most important strategies to reduce the severity of accidents at night.
In addition to advertising on the radio, television, and urban advertising, police, municipal, forensic, and health organizations are recommended to gift luminous stickers to females wearing dark clothing. Chain stores also could give these tags as an advertisement. On the other hand, chador and dark clothing can be produced, which are reflective or luminous at night, like worker clothing. The use of high-reflectance and luminous clothing and the provision of adequate street lighting and overhead lighting at pedestrian crossings, especially on arterial roads, are measures that can reduce the likelihood of accidents.

(2) For road markings like stop lines, crosswalks, and lane markings, retro-reflective substances should be utilized. By these substances, the light is reflected from vehicle headlights and from roadway illumination through glass beads with a particular design. Vests and other clothing for pedestrians should also be created with reflective substances. Investigations have indicated that the visibility of a pedestrian can be incremented by reflectorizing by a factor of 5 . The retro-reflective material should be utilized on backpacks, jackets, shoes, and other clothing.

(3) In rainy weather, pedestrians are more likely to be involved in accidents due to insufficient visibility of drivers, so pedestrians need to be aware of the possibility of a vehicle losing control and harming them on rainy days. Installing pedestrian flashing lights and pedestrian signs beside the roads, removing visual error factors (such as removing natural and abnormal obstacles and creating a good visual field) are engineering solutions to reduce the likelihood of accidents. Also, the use of an intelligent pedestrian alert system for approaching drivers (by pressing a special button by the pedestrian and transmitting the message to the LED signs in any direction of the approaching traffic) is recommended to enhance the safety of female passengers, especially at night, in arterial roads and during rainy weather.

\section{Data Availability}

The data used to support the findings of this study are currently under embargo while the research findings are commercialized. Requests for data, 3 months after publication of this article, will be considered by the corresponding author.

\section{Disclosure}

In this study, Iranian governmental organizations have not been partners and sponsors, and this study is purely for study purposes. 


\section{Conflicts of Interest}

The authors declare that they have no conflicts of interest.

\section{References}

[1] I. Bargegol, V. N. M. Gilani, and F. Jamshidpour, "Relationship between pedestrians' speed, density and flow rate of crossings through urban intersections (case study: rasht metropolis)," International Journal of Engineering-Transactions C: Aspects, vol. 30, no. 12, pp. 1814-1821, 2017.

[2] Movahhed and M. Bagheri, "The effect of rain on pedestrians crossing speed," Computational Research Progress in Applied Science \& Engineering (CRPASE), vol. 6, no. 3, 2020.

[3] Hikoui, H. Farhadi, and A. Mahmodzadeh, "Estimated total stadium emergency evacuation's time based on existing population analysis," Computational Research Progress in Applied Science \& Engineering (CRPASE), vol. 4, no. 2, 2018.

[4] I. Bargegol, V. Najafi Moghaddam Gilani, M. Ghasedi, and M. Ghorbanzadeh, "Delay modeling of un-signalized roundabouts using neural network and regression," Computational Research Progress in Applied Science \& Engineering (CRPASE), vol. 2, no. 1, 2016.

[5] I. Bargegol and M. Keyoumarsi, "An investigation on pedestrian accident severity in urban streets using path analysis," Computational Research Progress in Applied Science \& Engineering (CRPASE), vol. 2, no. 2, 2016.

[6] S. M. Hosseinian and V. Najafi Moghaddam Gilani, "Analysis of factors affecting urban road accidents in rasht metropolis," ENG Transactions, vol. 1, no. 1, pp. 1-4, 2020.

[7] S. M. Hosseinian, V. Najafi Moghaddam Gilani, P. Mehraban, and M. Arabani, "Investigation of moisture sensitivity and conductivity properties of inductive asphalt mixtures containing steel wool fiber," Advances in Civil Engineering, vol. 2020, Article ID 8890814, 2020.

[8] M. J. Samet, "Development of accident modification factors in two-lane highways," Computational Research Progress in Applied Science \& Engineering (CRPASE), vol. 2, no. 4, 2016.

[9] N. Nadimia, S. S. Naseralavi, A. M. Amiri, and A. Z. Mirhosseini, "Proposing a model for ranking hotspots in rural roads using a multi-criteria decision-making method," Computational Research Progress in Applied Science \& Engineering (CRPASE), vol. 3, 2017.

[10] Traffic police statistics and information center, Tehran, Iran, 2018 and 2019.

[11] M. Abolfazlzadeh and B. E. Gol, "Statistical analysis of the railway accidents causes in Iran," International Journal of Engineering, vol. 30, no. 12, pp. 1822-1830, 2017.

[12] N. Kamboozia, M. Ameri, and S. M. Hosseinian, "Investigation of effective factors in the severity of rural road accidents in guilan to determine the most effective factors and provide safety solutions," Road, vol. 29, no. 106, pp. 115-128, 2021.

[13] M. Nikookar, M. B. Movahhed, J. Ayoubinejad, V. Najafi Moghaddam Gilani, and S. M. Hosseinian, "Improving the moisture sensitivity of asphalt mixtures by simultaneous modification of asphalt binder and aggregates with carbon nanofiber and carbon nanotube," Advances in Civil Engineering, vol. 2021, Article ID 6682856, 2021.

[14] H. Behbahani and V. Najafi Moghaddam Gilani, "Analysis of crossing speed of the pedestrians in marked and unmarked crosswalks in the signalized and un-signalized intersections (case study: Rasht city)," IOP Conference Series: Materials Science and Engineering, vol. 245, no. 4, 2017.
[15] J. D. Turner, C. J. Simmons, and J. R. Graham, "High-visibility clothing for daytime use in work zones," Transportation Research Record: Journal of the Transportation Research Board, vol. 1585, no. 1, pp. 1-8, 1997.

[16] K. J. Clifton, C. V. Burnier, and G. Akar, "Severity of injury resulting from pedestrian-vehicle crashes: what can we learn from examining the built environment?" Transportation Research Part D: Transport and Environment, vol. 14, no. 6, pp. 425-436, 2009.

[17] R. A. Tyrrell, J. M. Wood, A. Chaparro, T. P. Carberry, B.-S. Chu, and R. P. Marszalek, "Seeing pedestrians at night: visual clutter does not mask biological motion," Accident Analysis \& Prevention, vol. 41, no. 3, pp. 506-512, 2009.

[18] C. V. Zegeer and M. Bushell, "Pedestrian crash trends and potential countermeasures from around the world," Accident Analysis \& Prevention, vol. 44, no. 1, pp. 3-11, 2012.

[19] J. M. Wood, P. Lacherez, and R. A. Tyrrell, "Seeing pedestrians at night: effect of driver age and visual abilities," Ophthalmic and Physiological Optics, vol. 34, no. 4, pp. 452-458, 2014.

[20] S. A. W. Borzendowski, A. A. S. Sewall, P. J. Rosopa, and R. A. Tyrrell, "Drivers' judgments of the effect of headlight glare on their ability to see pedestrians at night," Journal of Safety Research, vol. 53, pp. 31-37, 2015.

[21] A. F. Hefny, H. O. Eid, and F. M. Abu-Zidan, "Pedestrian injuries in the United Arab Emirates," International Journal of Injury Control and Safety Promotion, vol. 22, no. 3, pp. 203-208, 2015.

[22] M. Pour-Rouholamin and H. Zhou, "Investigating the risk factors associated with pedestrian injury severity in Illinois," Journal of Safety Research, vol. 57, pp. 9-17, 2016.

[23] D. K. Fekety, D. E. Edewaard, A. A. Stafford Sewall, and R. A. Tyrrell, "Electroluminescent materials can further enhance the nighttime conspicuity of pedestrians wearing retroreflective materials," Human Factors: The Journal of the Human Factors and Ergonomics Society, vol. 58, no. 7, pp. 976-985, 2016.

[24] M. M. Besharati and A. Tavakoli Kashani, "Which set of factors contribute to increase the likelihood of pedestrian fatality in road crashes?" International Journal of Injury Control and Safety Promotion, vol. 25, no. 3, pp. 247-256, 2018.

[25] R. Baireddy, H. Zhou, and M. Jalayer, "Multiple correspondence analysis of pedestrian crashes in rural Illinois," Transportation Research Record: Journal of the Transportation Research Board, vol. 2672, no. 38, pp. 116-127, 2018.

[26] V. Wickramasinghe, J. Edirisinghe, and S. Dissanayake, $P W$ 0803 Night Time Visibility of Crossing Pedestrians, BMJ Publishing Group Ltd., London, UK, 2018.

[27] H. Abdous and A. Mahmoudabadi, $P W 0580$ Vulnerability of Female Pedestrians in Different Crash Locations, A CaseStudy for iran, BMJ Publishing Group Ltd., London, UK, 2018.

[28] H. Yu, W. Li, and C. Chen, "Dynamic Gaussian barebones fruit fly optimizers with abandonment mechanism: method and analysis," Engineering with Computers, vol. 2020, pp. 1-29, 2020.

[29] J. Hu, H. Chen, A. A. Heidari et al., "Orthogonal learning covariance matrix for defects of grey wolf optimizer: insights, balance, diversity, and feature selection," Knowledge-Based Systems, vol. 213, Article ID 106684, 2020.

[30] C. Yu, M. Chen, and K. Cheng, "SGOA: annealing-behaved grasshopper optimizer for global tasks," Engineering with Computers, vol. 2021, pp. 1-28, 2021. 
[31] W. Shan, "Double adaptive weights for stabilization of moth flame optimizer: balance analysis, engineering cases, and medical diagnosis," Knowledge-Based Systems, vol. 214, Article ID 106728, 2020.

[32] J. Tu, H. Chen, J. Liu et al., "Evolutionary biogeography-based whale optimization methods with communication structure: towards measuring the balance," Knowledge-Based Systems, vol. 212, Article ID 106642, 2021.

[33] D. Zhao, L. Liu, F. Yu et al., "Chaotic random spare ant colony optimization for multi-threshold image segmentation of 2D Kapur entropy," Knowledge-Based Systems, vol. 216, Article ID 106510, 2020.

[34] H. Chen, A. A. Heidari, H. Chen, M. Wang, Z. Pan, and A. H. Gandomi, "Multi-population differential evolutionassisted Harris hawks optimization: framework and case studies," Future Generation Computer Systems, vol. 111, pp. 175-198, 2020.

[35] X. Xu and H.-l. Chen, "Adaptive computational chemotaxis based on field in bacterial foraging optimization," Soft Computing, vol. 18, no. 4, pp. 797-807, 2014.

[36] Y. Xu, H. Chen, J. Luo, Q. Zhang, S. Jiao, and X. Zhang, "Enhanced Moth-flame optimizer with mutation strategy for global optimization," Information Sciences, vol. 492, pp. 181203, 2019.

[37] N. A. Golilarz, H. Gao, and H. Demirel, "Satellite image denoising with harris hawks meta heuristic optimization algorithm and improved adaptive generalized Gaussian distribution threshold function," IEEE Access, vol. 7, pp. 57459-57468, 2019.

[38] N. A. Golilarz et al., "ORCA optimization algorithm: a new meta-heuristic tool for complex optimization problems," in Proceedings of the 2020 17th International Computer Conference on Wavelet Active Media Technology and Information Processing (ICCWAMTIP), Chengdu, China, December 2020.

[39] N. A. Golilarz, M. Mirmozaffari, T. A. Gashteroodkhani et al., "Optimized wavelet-based satellite image de-noising with multi-population differential evolution-assisted harris hawks optimization algorithm," IEEE Access, vol. 8, pp. 133076133085, 2020.

[40] A. Addeh, A. Khormali, and N. A. Golilarz, "Control chart pattern recognition using RBF neural network with new training algorithm and practical features," ISA Transactions, vol. 79, pp. 202-216, 2018.

[41] N. A. Golilarz, A. Addeh, H. Gao et al., "A new automatic method for control chart patterns recognition based on ConvNet and harris hawks meta heuristic optimization algorithm," IEEE Access, vol. 7, pp. 149398-149405, 2019.

[42] Tarhan, B. Cem, and M. Ranjbar, "A Review on multidisciplinary design optimization of dynamic engineering systems," Computational Research Progress in Applied Science \& Engineering (CRPASE), vol. 6, no. 3, 2020.

[43] S. Semir and M. Ranjbar, "A review on cutting tool optimization approaches," Computational Research Progress in Applied Science \& Engineering (CRPASE), vol. 6, no. 3, 2018.

[44] H. Ziari, H. Divandari, S. M. Seyed Ali Akbar, and S. M. Hosseinian, "Investigation of the effect of crumb rubber powder and warm additives on moisture resistance of SMA mixtures," Advances in Civil Engineering, vol. 2021, 2021, In press.

[45] A. Izadi, F. Jamshidpour, and H. Hadizadeh, "Evaluation of the performance of bus special lines according to indicators of quality and transport and its performance improvement using ultra-innovative intelligent models (Case study: Rasht city),"
Computational Research Progress in Applied Science \& Engineering (CRPASE), vol. 5, no. 4, 2019.

[46] X. Zhang et al., "Robust feature learning for adversarial defense via hierarchical feature alignment," Information Sciences, vol. 560, 2020.

[47] X. Zhang, T. Wang, W. Luo, and P. Huang, "Multi-level fusion and attention-guided CNN for image dehazing," IEEE Transactions on Circuits and Systems for Video Technology, 2020.

[48] X. Zhang, M. Fan, D. Wang, P. Zhou, and D. Tao, “Top-k feature selection framework using robust 0-1 integer programming," IEEE Transactions on Neural Networks and Learning Systems, pp. 1-15, 2020.

[49] X. Zhang, D. Wang, Z. Zhou, and Y. Ma, "Robust low-rank tensor recovery with rectification and alignment," IEEE Transactions on Pattern Analysis and Machine Intelligence, vol. 43, no. 1, pp. 238-255, 2019.

[50] X. Zhang, R. Jiang, T. Wang, and J. Wang, "Recursive neural network for video deblurring," IEEE Transactions on Circuits and Systems for Video Technology, 2020.

[51] X. Zhang, T. Wang, J. Wang, G. Tang, and L. Zhao, "Pyramid channel-based feature attention network for image dehazing," Computer Vision and Image Understanding, vol. 197-198, Article ID 103003, 2020.

[52] X. Zhao, D. Li, B. Yang, C. Ma, Y. Zhu, and H. Chen, "Feature selection based on improved ant colony optimization for online detection of foreign fiber in cotton," Applied Soft Computing, vol. 24, pp. 585-596, 2014.

[53] Y. Zhang, R. Liu, X. Wang, H. Chen, and C. Li, "Boosted binary Harris hawks optimizer and feature selection," Engineering with Computers, pp. 1-30, 2020.

[54] F. Jafari Golrokh, G. Azeem, and A. Hasan, "Eco-efficiency evaluation in cement industries: DEA malmquist productivity index using optimization models," Engineering Transactions, vol. 1, no. 1, 2020.

[55] F. Jafari Golrokh and A. Hasan, "A comparison of machine learning clustering algorithms based on the DEA optimization approach for pharmaceutical companies in developing countries," Engineering Transactions, vol. 1, no. 1, 2020.

[56] Y. Razieh, "An intelligent method for down syndrome detection in fetuses using ultrasound images and deep learning neural networks," Computational Research Progress in Applied Science \& Engineering (CRPASE), vol. 5, no. 3, 2019.

[57] V. Mahdi and A. Addeh, "An intelligent power prediction method for wind energy generation based on optimized fuzzy system," Computational Research Progress in Applied Science \& Engineering (CRPASE), vol. 5, no. 2, 2019.

[58] Shourabi, R. Zamani, and M. R. Moradian, "An intelligent method based on model predictive torque control and optimized ANFIS for induction motor speed control," Computational Research Progress in Applied Science \& Engineering (CRPASE), vol. 4, no. 4, 2018.

[59] Iran Statistical Center, Official Results of Census of Populations and Houses of Iran, Iran Statistical Center, Tehran, Iran, 2016.

[60] I. Bargegol, V. N. M. Gilani, and S. Farghedayn, "Analysis of the effect of vehicles conflict on pedestrian's crossing speed in signalized and un-signalized intersection," Advances in Environmental Biology, vol. 8, no. 21, pp. 502-510, 2014.

[61] R. Eisinga, T. Heskes, B. Pelzer, and M. T. Grotenhuis, "Exact $p$ values for pairwise comparison of Friedman rank sums, with application to comparing classifiers," BMC Bioinformatics, vol. 18, no. 1, p. 68, 2017.

[62] S. M. Hosseinian, V. Najafi Moghaddam Gilani, H. T. Amoli, M. Nikookar, and A. Orouei, "Presentation of analytical 
methods for better decision making about the most important factor influencing rural accidents," Mathematical Problems in Engineering, vol. 2021, Article ID 5564269, 2021.

[63] T. Sanaz, A. Aslani, and H. Forotan, "Prediction of energy consumption by using regression model," Computational Research Progress in Applied Science \& Engineering, vol. 2, no. 3, 2016.

[64] A. Mahyar, "Rough-set theory in solving road pavement management problems (case study: Ahwaz-Shush highway)," Computational Research Progress in Applied Science \& Engineering, vol. 3, no. 2, 2017.

[65] N. Kamboozia, M. Ameri, and S. M. Hosseinian, "Statistical analysis and presentation of accident prediction model leading to injuries and deaths of pedestrians in rural roads of Gilan," Journal of Transportation Research, 2020.

[66] R. K. Young and J. Liesman, "Estimating the relationship between measured wind speed and overturning truck crashes using a binary logit model," Accident Analysis \& Prevention, vol. 39, no. 3, pp. 574-580, 2007.

[67] N. Amiri Golilarz and H. Demirel, "Thresholding neural network (TNN) based noise reduction with a new improved thresholding function," Computational Research Progress in Applied Science \& Engineering, vol. 03, no. 02, 2017.

[68] H. Behbahani, G. H. Hamedi, and V. Najafi Moghaddam Gilani, "Predictive model of modified asphalt mixtures with nano hydrated lime to increase resistance to moisture and fatigue damages by the use of deicing agents," Construction and Building Materials, vol. 265, Article ID 120353, 2020.

[69] Y. ZhangR. Liu et al., "Towards augmented kernel extreme learning models for bankruptcy prediction: algorithmic behavior and comprehensive analysis," Neurocomputing, vol. 430, 2020.

[70] H.-L. Chen, G. Wang, C. Ma, Z.-N. Cai, W.-B. Liu, and S.-J. Wang, "An efficient hybrid kernel extreme learning machine approach for early diagnosis of Parkinson's disease," Neurocomputing, vol. 184, pp. 131-144, 2016.

[71] L. Hu, G. Hong, J. Ma, X. Wang, and H. Chen, "An efficient machine learning approach for diagnosis of paraquat-poisoned patients," Computers in Biology and Medicine, vol. 59, pp. 116-124, 2015.

[72] L. Shen, H. Chen, Z. Yu et al., "Evolving support vector machines using fruit fly optimization for medical data classification," Knowledge-Based Systems, vol. 96, pp. 61-75, 2016.

[73] J. Xia, H. Chen, Q. Li et al., "Ultrasound-based differentiation of malignant and benign thyroid nodules: an extreme learning machine approach," Computer Methods and Programs in Biomedicine, vol. 147, pp. 37-49, 2017.

[74] C. Li, L. Hou, B. Y. Sharma et al., "Developing a new intelligent system for the diagnosis of tuberculous pleural effusion," Computer Methods and Programs in Biomedicine, vol. 153, pp. 211-225, 2018.

[75] X. Zhao, X. Zhang, Z. Cai et al., "Chaos enhanced grey wolf optimization wrapped ELM for diagnosis of paraquat-poisoned patients," Computational Biology and Chemistry, vol. 78, pp. 481-490, 2019.

[76] M. Wang and H. Chen, "Chaotic multi-swarm whale optimizer boosted support vector machine for medical diagnosis," Applied Soft Computing Journal, vol. 88, 2020.

[77] M. Wang, H. Chen, B. Yang et al., “Toward an optimal kernel extreme learning machine using a chaotic moth-flame optimization strategy with applications in medical diagnoses," Neurocomputing, vol. 267, pp. 69-84, 2017.

[78] H. Behbahani, V. Najafi Moghaddam Gilani, A. Amini, N. Kamboozia, and S. M. Hosseinian, "Fuzzy-neural analysis of pedestrian flow crossing urban intersections," in Proceedings of the 18th International Conference on Traffic \& Transportation Engineering, Tehran, Iran, January 2020.

[79] V. Najafi Moghaddam Gilani, S. M. Hosseinian, and M. Nikookar, "Presentation of a new deicer with the least moisture and fatigue failures in asphalt mixtures," Arabian Journal for Science and Engineering, 2021.

[80] X. Zhang, M. Fan, D. Wang, P. Zhou, and D. Tao, “Top- $k$ feature selection framework using robust 0-1 integer programming," IEEE Transactions on Neural Networks and Learning Systems, 2020.

[81] X. Zhang, R. Jiang, T. Wang, and J. Wang, "Recursive neural network for video deblurring," IEEE Transactions on Circuits and Systems for Video Technology, 2020.

[82] V. Najafi Moghaddam Gilani, S. M. Hosseinian, H. Behbahani, and G. H. Hamedi, "Prediction and paretobased multi-objective optimization of moisture and fatigue damages of asphalt mixtures modified with nano hydrated lime," Construction and Building Materials, vol. 261, Article ID 120509, 2020.

[83] V. Najafi Moghaddam Gilani, S. M. Hosseinian, D. Safari, and M. B. Movahhed, "Investigation of the impact of deicer materials on thermodynamic parameters and its relationship with moisture susceptibility in modified asphalt mixtures by carbon nanotube," Arabian Journal for Science and Engineering, 2020.

[84] H. Behbahani, H. Ziari, A. Amini, V. Najafi Moghaddam Gilani, and R. Salehfard, "Investigation of un-signalized roundabouts delay with adaptive-network-based fuzzy inference system and fuzzy logic," Computational Research Progress in Applied Science \& Engineering, vol. 2, no. 04, pp. 1-7, 2016.

[85] J. Qian, S. Feng, Y. Li et al., "Single-shot absolute 3D shape measurement with deep-learning-based color fringe projection profilometry," Optics Letters, vol. 45, no. 7, pp. 1842-1845, 2020.

[86] H. Chen, A. Chen, L. Xu et al., "A deep learning CNN architecture applied in smart near-infrared analysis of water pollution for agricultural irrigation resources," Agricultural Water Management, vol. 240, Article ID 106303, 2020.

[87] A. Mahani, P. Bazoobandi, S. M. Hosseinian, and H. Ziari, "Experimental investigation and multi-objective optimization of fracture properties of asphalt mixtures containing nanocalcium carbonate," Construction and Building Materials, vol. 285, Article ID 122876, 2021.

[88] V. Najafi Moghaddam Gilani, S. M. Hosseinian, G. H. Hamedi, and D. Safari, "Presentation of predictive models for two-objective optimization of moisture and fatigue damages caused by deicers in asphalt mixtures," Journal of Testing and Evaluation, vol. 49, 2020 In press.

[89] I. Yilmaz and O. Kaynar, "Multiple regression, ANN (RBF, MLP) and ANFIS models for prediction of swell potential of clayey soils," Expert Systems with Applications, vol. 38, no. 5, pp. 5958-5966, 2011.

[90] H. T. Abdelwahab and M. A. Abdel-Aty, "Artificial neural networks and logit models for traffic safety analysis of toll plazas," Transportation Research Record: Journal of the Transportation Research Board, vol. 1784, no. 1, pp. 115-125, 2002.

[91] R. U. Khan, X. Zhang, R. Kumar, A. Sharif, N. A. Golilarz, and M. Alazab, "An adaptive multi-layer botnet detection technique using machine learning classifiers," Applied Sciences, vol. 9, no. 11, p. 2375, 2019. 
[92] M. Kashaninejad, A. A. Dehghani, and M. Kashiri, "Modeling of wheat soaking using two artificial neural networks (MLP and RBF)," Journal of Food Engineering, vol. 91, no. 4, pp. 602-607, 2009.

[93] A. Addeh and M. Iri, "Brain tumor type classification using deep features of MRI images and optimized RBFNN," Engineering Transactions, vol. 2, no. 1, 2021.

[94] N. Kamboozia, M. Ameri, and S. M. Hosseinian, "Statistical analysis and accident prediction models leading to pedestrian injuries and deaths on rural roads in Iran," International Journal of Injury Control and Safety Promotion, vol. 27, no. 4, pp. 493-509, 2020.

[95] G. H. Hamedi, M. R. Esmaeeli, V. Najafi Moghaddam Gilani, and S. M. Hosseinian, "The effect of aggregate-forming minerals on thermodynamic parameters using surface free energy concept and its relationship with the moisture susceptibility of asphalt mixtures," Advances in Civil Engineering, vol. 2021, Article ID 8818681, , 2021.

[96] J. B. Yang, K. Q Shen, C. J Ong, and X. P Li, “Feature selection for MLP neural network: the use of random permutation of probabilistic outputs," IEEE Transactions on Neural Networks, vol. 20, no. 12, pp. 1911-1922, 2009.

[97] T. Saito and M. Rehmsmeier, "Precrec: fast and accurate precision-recall and ROC curve calculations in R," Bioinformatics, vol. 33, no. 1, pp. 145-147, 2017.

[98] E. LeDell, M. Petersen, and M. van der Laan, "Computationally efficient confidence intervals for cross-validated area under the ROC curve estimates," Electronic Journal of Statistics, vol. 9, no. 1, p. 1583, 2015.

[99] T. Fawcett, "An introduction to ROC analysis," Pattern Recognition Letters, vol. 27, no. 8, pp. 861-874, 2006. 